DANIELA SCARABUCCI JANONES

\title{
ESTUDO DA PRESENÇA DE OSTEOADERINA DURANTE A OSSIFICAÇÃ̄O INTRAMEMBRANOSA E ENDOCONDRAL ATRAVÉS DE IMUNOCITOQUÍMICA E WESTERN BLOTTING
}

Tese apresentada ao Instituto de Ciências Biomédicas da Universidade de São Paulo, para obtenção do título de Doutor em Ciências (Biologia Celular e Tecidual).

São Paulo

2009 


\section{ESTUDO DA PRESENÇA DE OSTEOADERINA DURANTE A OSSIFICAÇÃ̃O INTRAMEMBRANOSA E ENDOCONDRAL ATRAVÉS DE IMUNOCITOQUÍMICA E WESTERN BLOTTING}

Tese apresentada ao Instituto de Ciências Biomédicas da Universidade de São Paulo, para obtenção do título de Doutor em Ciências.

Área de Concentração

Biologia Celular e Tecidual

Orientador

Prof. Dr. Victor Elias Arana-Chavez

São Paulo

2009 
DADOS DE CATALOGAÇÃO NA PUBLICAÇÃO (CIP)

Serviço de Biblioteca e Informação Biomédica do

Instituto de Ciências Biomédicas da Universidade de São Paulo

(c) reprodução total

Janones, Daniela.

Estudo da presença de osteoaderina durante a ossificação

intramembranosa e endocondral através de imunocitoquímica e Western blotting / Daniela Janones. -- São Paulo, 2009.

Orientador: Victor Elias Arana Chavez.

Tese (Doutorado) - Universidade de São Paulo. Instituto de Ciências Biomédicas. Departamento de Biologia Celular e do Desenvolvimento. Área de concentração: Biologia Celular e Tecidual. Linha de pesquisa: Biologia dos tecidos mineralizados.

Versão do título para o inglês: Study of the osteoadherin presence during the intramembranous and endochondral ossification by immunocytochemistry and western blotting analysis .

Descritores: 1. Osteoaderina 2. Ossificação Intramebranosa Ossificação Endocondral 4. Mineralização Óssea 5. 3. Imunocitoquímica 6. Western Blotting I. Chavez, Victor Elias Arana II. Universidade de São Paulo. Instituto de Ciências Biomédicas. Programa de Pós-Graduação em Biologia Celular e Tecidual III. Título. 



\section{UNIVERSIDADE DE SÃO PAULO \\ INSTITUTO DE CIÊNCIAS BIOMÉDICAS}

Candidato(a): $\quad$ Daniela Janones.

Título da Tese: $\quad$ Estudo da presença de osteoaderina durante a ossificação intramembranosa e endocondral através de imunocitoquímica e Western blotting .

Orientador(a): $\quad$ Victor Elias Arana Chavez.

A Comissão Julgadora dos trabalhos de Defesa da Tese de Doutorado, em sessão pública realizada a considerou
( ) Aprovado(a)
( ) Reprovado(a)

$\begin{array}{ll}\text { Examinador(a): } & \text { Assinatura: } \\ & \text { Nome: ....... } \\ & \text { Instituição: } \\ \text { Examinador(a): } & \text { Assinatura: } \\ & \text { Nome: ....... } \\ & \text { Instituição: } \\ \text { Examinador(a): } & \text { Assinatura: } \\ & \text { Nome: ........ } \\ & \text { Instituição: } \\ \text { Examinador(a): } & \begin{array}{l}\text { Assinatura: } \\ \text { Nome: ........ }\end{array} \\ & \text { Instituição: } \\ & \text { Assinatura: } \\ \text { Presidente: } & \text { Nome: ......... } \\ & \text { Instituição: }\end{array}$ 


\section{Certificado}

Certificamos que o protocolo registrado sob $\mathrm{n}^{\circ} \mathbf{0 7 3}$ nas fls. 59 do livro 02 para uso de animais em experimentação, sob a responsabilidade de Victor Elias AranaChavez, Coordenador(a) da Linha de pesquisa "Estudo imunocitoquimico da presença de proteoglicanas durante a ossificação intramembranosa e endocondral' do qual participou(aram) o(s) alunos Daniela Scarabucci Janones está de acordo com os Principios Éticos de Experimentação Animal adotado pelo Colégio Brasileiro de Experimentação Animal (COBEA) e foi aprovado pela COMISSÃO DE ÉTICA EM EXPERIMENTAÇÃO ANIMAL (CEEA) em 18.09.08, com validade de 3 anos.

São Paulo, 19 de setembro de 2008.

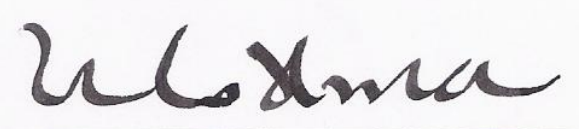

Prof. Dr. Wothan TAVARES DE LIMA

Coordenador CEEA - ICB/USP

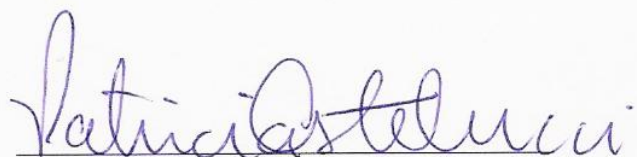

Profa. Dra. PATRÍCIA CASTELUCCI

Secretária CEEA - ICB/USP 
Ao meu pai Luiz,

Que, mesmo não estando mais entre nós, foi sempre um motivo para não desistir...

À minha mãe Romilda,

Que por tantas vezes saiu da sua casa para cuidar da minha...

Pelo amor incondicional e apoio constante!

Aos meus irmãos Renata e Luizinho,

Por serem meus grandes amigos e importantes exemplos de competência e profissionalismo!

Ao meu marido Sandro e meu filho Arthur, Por terem abdicado tanto tempo do nosso convívio familiar para que eu pudesse crescer... Espero ser um dia tão grande quanto vocês!!! 


\section{AGRADECIMENTOS}

Em especial ao Prof. Dr. Victor Elias Arana-Chavez, orientador deste trabalho, por ter me apresentado à vida científica, por ter me dado a honra de fazer parte do seu laboratório por tanto anos, por ser fonte de inspiração na vida acadêmica, por ter sido muito mais que simplesmente meu orientador em pesquisa, mas um exemplo pessoal de caráter e competência!

"Somos o que repetidamente fazemos. A excelência, portanto, não é um feito, mas um hábito" (Aristóteles).

Obrigada Victor por me permitir usufruir de sua excelência!

À todos os docentes do departamento de Biologia Celular e do Desenvolvimento pelos ensinamentos e disponibilidade.

Aos queridos Gaspar e Edson, técnicos do setor de microscopia eletrônica, pela responsabilidade, eficiência e capricho do trabalho desenvolvido. Mais do que por isso, Ihes serei eternamente grata pelo respeito e carinho com que se dispuseram a me ajudar sempre!

As secretárias do departamento de Biologia Celular e do Desenvolvimento, em especial à Celiana, secretária do Programa de Pós Graduação, pela atenção e cooperação constantes, suas dicas foram importantíssimas para que eu conseguisse cumprir minhas obrigações burocráticas mesmo estando distante.

Aos técnicos de Laboratório Leandro, Emilia, Nancy, e, em especial, à Fernanda Barrence, por sua amizade e disposição em ajudar.

Aos demais funcionários do Departamento de Biologia Celular e do Desenvolvimento, pelo auxílio e disponibilidade. 
Aos amigos queridos do Laboratório de Biologia dos Tecidos Mineralizados Tatiani, Vivian, Bethinha, Natasha, Fernanda, Lorraine, Eloíza, Tais, Karla, Felipe, Márcio, Newton e Lu Massa, pela generosidade nos inúmeros favores prestados, por tornarem nosso ambiente de trabalho tão agradável e pela amizade sincera que com o perdão do chavão - o tempo e a distância não irão apagar!!

Em especial à minha grande amiga Tati, por ter tomado para si os problemas que eram meus e por tê-los resolvidos com tamanha dedicação! Por ser amiga no sentido maior que essa palavra possa ter. Querida Tatilene, você é, simplesmente, o MÁXIMO!!

À minha amiga Mara Rúbia, por tantas sugestões e apoio durante toda minha vida de pós-graduanda, não somente nos trabalhos científicos, mas, principalmente, nos meus problemas existenciais !!! Adoro você, pequena!

Aos colegas e alunos do UNIEURO, por me fazerem acreditar, diariamente, que a busca do conhecimento sempre nos leva a um lugar melhor...

À Nara, minha secretária em casa, que não poupou esforços nos cuidados com a casa e com meu filho para que eu pudesse estar em São Paulo trabalhando com tranquilidade.

A Deus, por se mostrar em cada momento de dificuldade e de conquista, por me fazer mais forte a cada obstáculo e por fazer me perceber tão frágil frente a Sua grandeza.

E a todos que direta ou indiretamente, contribuíram para o cumprimento de mais uma etapa em minha formação profissional.

MUITO OBRIGADA!!! 


\section{RESUMO}

JANONES, D.S. Estudo da presença de osteoaderina durante a ossificação intramembranosa e endocondral através de imunocitoquímica e Western Blotting. Tese (Doutorado) - Instituto de Ciências Biomédicas, Universidade de São Paulo, São Paulo, 2009.

A osteoaderina (OSAD) é uma proteoglicana queratan-sulfato isolada inicialmente do osso bovino. Embora sua distribuição nos tecidos mineralizados tenha sido descrita sugerindo um papel na biomineralização, sua função específica neste processo permanece pouco compreendida. Neste estudo foi feita uma comparação do momento em que a OSAD aparece durante a ossificação intramembranosa e endocondral, além de correlacioná-lo com os estágios iniciais de mineralização. O osso parietal de fetos de ratos Wistar com 17, 18 e 21 dias de vida intra-uterina (v.i.u.) e o côndilo mandibular de ratos Wistar com 30 dias de vida foram removidos. Alguns espécimes foram congelados em nitrogênio líquido, enquanto outros foram fixados em glutaraldeído $0.1 \%$ + formaldeído a $4 \%$ sob irradiação de microondas. Algumas amostras foram descalcificadas em EDTA 4.13\%, e outras foram deixadas sem descalcificação, passando posteriormente por desidratação em concentrações crescentes de etanol e infiltradas em resina LR White. A expressão de OSAD foi analisada por imunocitoquímica e Western blotting. Cortes ultra-finos foram incubados com anticorpo policlonal de coelho anti-OSAD. Tanto na ossificação intramembranosa quanto na endocondral, as partículas de ouro estiveram sempre uniformemente distribuídas no citoplasma dos osteoblatos e na matriz extracelular; entretanto, a imunomarcação só foi visível na matriz quando o estágio fibrilar de mineralização teve início, tendo se mantido constante a quantidade de proteoglicana a partir de então. A análise feita através de Western blotting com o mesmo anticorpo revelou que os fetos com 17 dias v.i.u. continham pouco menos OSAD que os fetos com 18 dias vi.u.u, enquanto a imunorreatividade foi muito fraca para os fetos com 21 dias vi.u. Os resultados sugerem que a OSAD tem um papel na mineralização da matriz extracelular, atuando, provavelmente como organizadora do arcabouço da matriz ou retendo os cristais de mineral, além de exercer atividades de adesão entre os componentes desta matriz. 
Palavras- Chave: Osteoaderina • Ossificação Intramembranosa • Ossificação Endocondral • Mineralização Óssea • Imunocitoquímica • Western Blotting. 


\section{ABSTRACT}

JANONES, D.S. Study of the osteoadherin presence during the intramembranous and endochondral ossification by immunocytochemistry and western blotting analysis. Doctor Thesis Instituto de Ciências Biomédicas, Universidade de São Paulo, São Paulo, 2009.

Osteoadherin (OSAD) is a keratan sulfate proteoglycan firstly isolated from bovine bone. Although the distribution of OSAD in mineralized tissues had been described suggesting a role in biomineralization, its specific role remains poorly understood. The present study compared the appearance of OSAD during both intramembranous and endochondral ossification and correlated it with early stages of mineralization. Parietal bone of 17, 18 and 21 days-old fetus and mandibular condyle of 30 days-old Wistar rats were removed. Some specimens were frozen in liquid nitrogen while others were fixed in $0.1 \%$ glutaraldehyde + $4 \%$ formaldehyde under microwave irradiation. Some specimens were left undecalcified, while others were decalcified in $4.13 \%$ EDTA, dehydrated in graded concentrations of ethanol and embedded in LR White resin. The expression of OSAD was analyzed by immunocytochemistry and Western blotting. Ultrathin sections were incubated with a polyclonal rabbit antibody against rat OSAD. In both intramembranous and endochondral ossification the gold particles were always uniformly distributed in the cytoplasm of osteoblasts but they only appeared in the mineralizing matrix when the fibrilar stage was taking place, remaining as a component of the mineralized bone matrix. Western blots carried out with the same antibody revealed that 17-days-old embryos contained slightly less OSAD than 18- days-old fetus, while immunoreactivity was weak in 21 days-old fetus. The results suggest that OSAD play a role in collagen fibril mineralization maybe as an organizer of matrix assembly or by retaining the mineral crystals into the matrix, besides exerting binding activities among bone matrix components.

KeyWords: Osteoadherin - Intramembranous Ossification - Endochondral Ossification • Bone Mineralization • Immunocytochemistry • Western Blotting. 


\section{LISTA DE ABREVIATURAS E SIGLAS}

${ }^{\circ} \mathrm{C}$

BMP

BSA

BSP

$\mathrm{Ca}_{10}\left[\mathrm{PO}_{4}\right]_{6}[\mathrm{OH}]_{2}$

DTT

$\mathrm{HA}$

Hepes

$\mathrm{KCl}$

MEC

MET

$\mathrm{MgCl}$

PBS

$\mathrm{pH}$

rpm

SDS

SDS- PAGE

TA

TBS

TTBS

TGF

GAGs

EDTA

OSAD

v.i.u.

PGs

PPRL

N-terminal graus Celsius

sigla em inglês para bone morphogenetic protein

albumina de soro bovino

sigla em inglês para bone sialoprotein

fórmula química da hiodroxiapatita

ácido diclorocianúrico DTT (C3C12Na3NaO3 . 2H2O)

hidroxiapatita

(4-(2- hydroxyethyl)-1- perazineethanesulfonic acid

Cloreto de Potássio

matriz extracelular

microscopia eletrônica de transmissão

Cloreto de Magnésio

sigla em inglês para phosphate buffer solution

potencial hidrogeniônico

rotações por minuto

sódio dodecil sulfato

gel desnaturante contendo poliacrilamida e sódio dodecil sulfato

temperatura ambiente

solução salina Tris- tamponada

solução salina Tris- tamponada + detergente Tween 20

sigla em inglês para transforming growth factor

glicosaminoglicanas

sigla em inglês para Ethylenediamine tetraacetic acid

osteoaderina

vida intra uterina

proteoglicanas

pequena proteoglicana rica em leucina

região amino-terminal 


\section{LISTA DE SÍMBOLOS}

$\begin{array}{ll}\% & \text { sinal matemático indicativo de porcentagem } \\ \mu \mathrm{L} & \text { microlitros } \\ \mu \mathrm{m} & \text { micrômetros } \\ \mathrm{kDa} & \text { kiloDalton } \\ \mathrm{Kg} & \text { Kilo Gramas } \\ \mathrm{kV} & \text { kiloVolt } \\ \mathrm{M} & \text { molar } \\ \mathrm{mL} & \text { mililitro } \\ \mathrm{mM} & \text { miliMolar } \\ \mathrm{nm} & \text { nanômetro } \\ \mathrm{V} & \text { Volts } \\ \beta & \text { beta }\end{array}$


1 INTRODUÇÃO

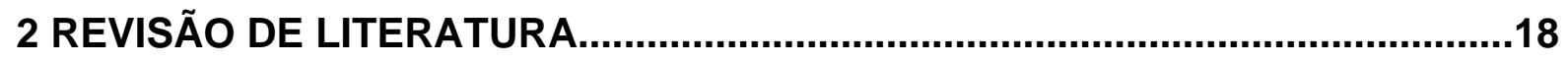

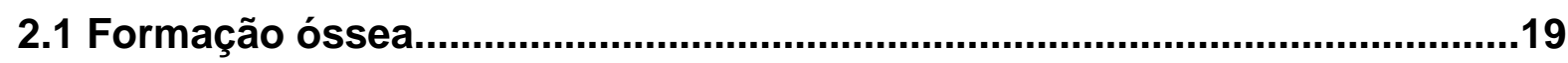

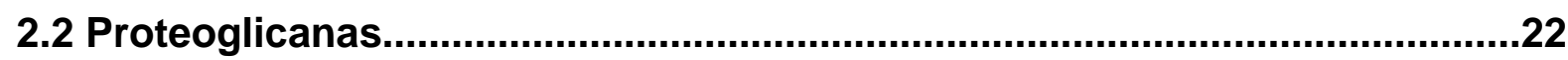

2.2.1 Proteoglicanas pequenas ricas em leucina ..................................................

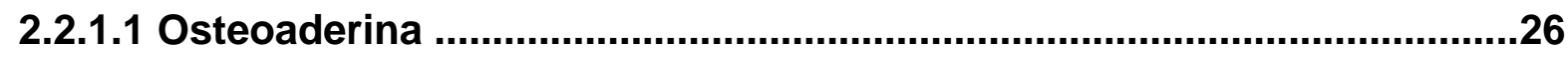

2.3 Imunocitoquímica e processamento com microondas..................................28

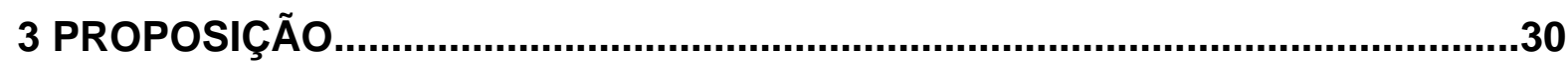

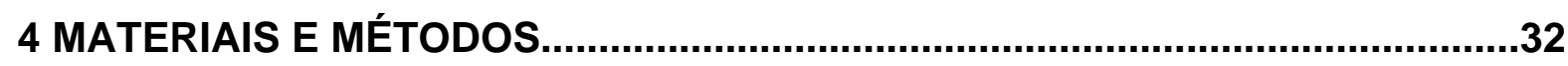

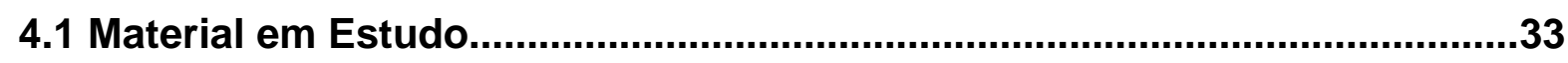

4.2 Obtenção e Processamento dos Espécimes................................................33

4.3 Imunocitoquímica pós- inclusão com ouro coloidal....................................35

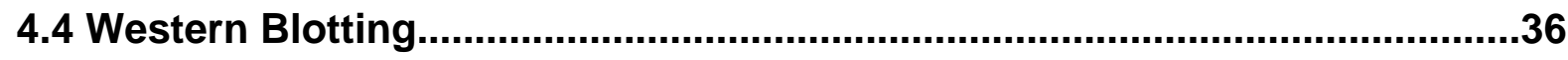

5 RESULTADOS

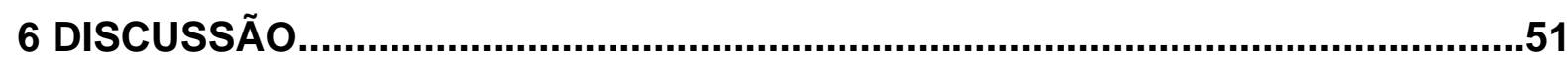

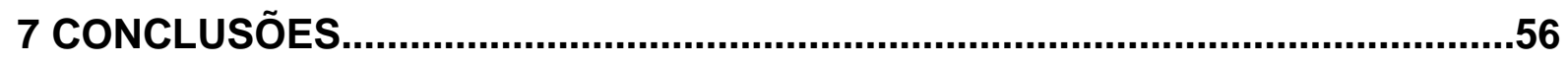

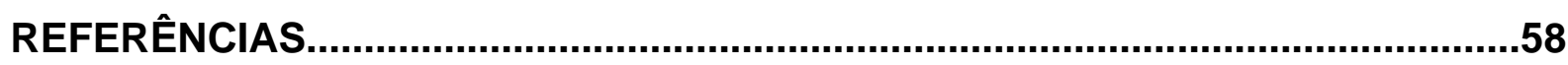


1 INTRODUÇÃO 
A formação do tecido ósseo é um processo complexo que resulta em um tecido mineralizado rico em colágeno. Os cristais de mineral são depositados sobre a matriz orgânica secretada pelos osteoblastos, que consiste em colágeno tipo I associado a proteínas não- colágenas e proteoglicanas (PGs). Há fortes evidências de que os constituintes químicos desta matriz sejam essenciais na determinação das características do mineral formado (OMELON et al., 2009).

A maioria dos ossos do complexo crânio- facial se desenvolve via ossificação intramembranosa, durante a qual células ectomesenquimais derivadas da crista neural se condensam e se diferenciam em osteoblastos que formam um osso imaturo. Os ossos longos, por outro lado, se desenvolvem através da ossificação endocondral, em que células mesenquimais derivadas do mesoderma se condensam e se diferenciam em condroblastos e formam um modelo de cartilagem hialina, que, subseqüentemente, sofre mineralização da matriz cartilaginosa e morte dos condrócitos. As células mesenquimais circundantes se diferenciam em osteoblastos que secretam osso sobre a cartilagem mineralizada (KARSENTY, 2003; KARSENTY e WAGNER, 2002; GILBERT, 2006). No crânio, poucas regiões se desenvolvem por ossificação endocondral, dentre elas está 0 côndilo mandibular (SINGH e DETAMORE, 2009). Embora vários mecanismos do processo de nucleação mineral sejam ainda pouco compreendidos, já está claro que o início da mineralização ocorre de maneira diferente na ossificação intramembranosa e na ossificação endocondral. $\mathrm{Na}$ ossificação intramembranosa os osteoblastos liberam vesículas da matriz, dentro das quais ocorre a nucleação dos primeiros cristais de mineral. Este processo não acontece na ossificação endocondral, em que a nucleação dos cristais ocorre a partir do contato com cartilagem mineralizada subjacente (NAHAR et al., 2008).

Vários estudos revelaram que os ossos formados por estes dois tipos de ossificação exibem diferenças em sua composição, tanto na fase orgânica, quanto na fase inorgânica (VAN DEN BOS et al., 2008). Durante os eventos morfogenéticos de formação óssea, ocorrem mudanças na composição da matriz extracelular, incluindo diferentes tipos de colágenos e proteínas não-colágenas 
(VAN DEN BOS et al., 2008; SUTTAPREYASRI et al., 2006), além da expressão de grupos específicos de PGs (WADDINGTON et al., 2003). Este processo dinâmico é altamente regulado por fatores transcricionais, moléculas sinalizadoras, hormônios e fatores de crescimento (ERLEBACHER et al., 1995; ABZHANOV et al., 2007).

As PGs são moléculas que participam da organização da matriz extracelular dos tecidos conjuntivos e têm efeitos importantes nas interações matriz- matriz e célula- matriz (HOCKING et al., 1998). Em contraste com a maioria das espécies de PGs encontradas na cartilagem e nos tecidos conjuntivos, as PGS dos tecidos minerais, como o osso, pertencem à família das pequenas proteoglicanas ricas em leucina (PPRL), que possuem apenas uma ou duas cadeias glicídicas e peso molecular abaixo de $100 \mathrm{KDa}$ (WADDINGTON et al., 2003). As PPRL formam uma grande família composta por 17 membros que, embora possuam homologia estrutural entre si, se desenvolveram a partir de genes diferentes, adquiriram funções únicas e sofreram um alto grau de sofisticação estrutural (SCHAEFER e IOZZO, 2008).

Pouco se conhece sobre o destino das PGs durante a ossificação. Enquanto a função das proteoglicanas decorin e biglican tenha sido fartamente analizada nos tecidos conjuntivos, o papel da osteoaderina (OSAD), uma proteoglicana queratan-sulfato rica em leucina e ácido aspártico, não é completamente entendido. Sua presença foi inicialmente detectada em osso bovino (WENDEL et al., 1998). Posteriormente, seu RNAm foi detectado em osteoblastos, odontoblastos e ameloblastos de ratos, além de odontoblastos humanos (BUCHAILLE et al., 2000; LUCCHINI et al., 2002). Extracelularmente, foi descrita a presença de OSAD no osso alveolar, pré-dentina e esmalte (COUBLE et al., 2004; RAMSTAD et al., 2003). Em estudos mais recentes, análises in vitro da diferenciação e maturação de osteoblastos têm sugerido que a OSAD seria um marcador de osteoblastos diferenciados, quando regulada por TGF- 1 e BMP-2 (REHN et al., 2006). Além disso, osteoblastos em cultura aumentaram sua maturação através da "super expressão" de OSAD (REHN et al., 2008). 
Todos estes estudos especulam que a OSAD tem potencial para afetar a mineralização, mas sua aparição durante o desenvolvimento ósseo não foi analizada. O objetivo deste estudo foi comparar a presença da OSAD durante a ossificação intramembranosa e endocondral fazendo uma correlação com os estágios iniciais de mineralização, uma vez que o começo da deposição de mineral exibe diferenças nos dois processos de formação óssea. 
2 REVISÃO DE LITERATURA 


\subsection{Formação Óssea}

Os tecidos conjuntivos em geral são constituídos por uma extensa matriz extracelular. O tecido ósseo é um tecido de natureza conjuntiva composto por células e abundante matriz, que se caracteriza por possuir uma porção inorgânica predominante, sob a forma de hidroxiapatita ( $\left.\mathrm{HA}-\mathrm{Ca}_{10}\left[\mathrm{PO}_{4}\right]_{6}[\mathrm{OH}]_{2}\right)$, associada a uma fase orgânica, cujo principal constituinte é o colágeno tipo I, além dos componentes não colágenos, como glicoproteínas, fosfoproteínas e proteoglicanas (PGs) (KATCHBURIAN e ARANA-CHAVEZ, 2004).

A formação óssea dos mamíferos é um processo coordenado temporal e espacialmente, que se inicia no período embrionário através da condensação e diferenciação de células progenitoras. A osteogênese pode ocorrer por dois mecanismos: através da ossificação intramembranosa, em que células mesenquimais derivadas da crista neural se diferenciam diretamente em osteoblastos secretores da matriz óssea; ou por ossificação endocondral, processo no qual a diferenciação das células mesenquimais do mesoderma levam à formação inicial de um molde cartilaginoso, que é, posteriormente, substituído por osso (KARSENTY e WAGNER, 2002; KARSENTY, 2003; GILBERT, 2006).

A ossificação intramembranosa é o processo através do qual se formam os ossos frontal, parietal e de partes do occipital, do temporal e dos maxilares superior e inferior. Neste processo, o osso se desenvolve a partir de células mesenquimais indiferenciadas, que proliferam e se condensam em regiões cuja vascularização é aumentada. Então, as células se diferenciam em osteoblastos maduros e passam a sintetizar e secretar as moléculas características da matriz orgânica do tecido ósseo, formando o osteóide - porção imatura e ainda não mineralizada da matriz óssea (JIANG et al., 2002; HELMS e SCHNEIDER, 2003; KATCHBURIAN e ARANA-CHAVEZ, 2004).

Durante a subseqüente mineralização da matriz osteóide, através da deposição de cálcio e fosfato, osteoblastos destinados a se transformarem em osteócitos diminuem o ritmo da sua produção de matriz em comparação com os osteoblastos vizinhos e, dessa maneira, acabam se tornando passivamente 
aprisionados na matriz óssea. Ao redor das espículas ósseas formadas inicialmente, mais células mesenquimais se organizam e formam o periósteo, que reveste o osso externamente. As células que povoam a região mais interna do periósteo se diferenciam em osteoblastos e iniciam a formação de uma nova lâmina óssea. Assim, várias camadas ósseas vão sendo formadas (FRANZODENDAAL , 2006; JUNQUEIRA e CARNEIRO, 2008).

Por outro lado, no processo de ossificação endocondral, o molde inicial de cartilagem hialina é completamente avascular e contém condrócitos que secretam proteínas específicas da matriz cartilaginosa e se dividem rapidamente. Na periferia do modelo cartilaginoso, algumas células formam o pericôndrio e proliferam, contribuindo para o crescimento lateral do molde. Células do pericôndrio se diferenciam em osteoblastos e secretam matriz óssea que se mineraliza, formando um colar ósseo ao redor da diáfise. Uma vez que este colar ósseo é formado, os condrócitos da porção central da cartilagem passam por um processo de maturação, tornando-se hipertróficos. A matriz circundante dos condrócitos hipertróficos se mineraliza enquanto capilares, partindo do periósteo, atravessam o cilindro ósseo e penetram na cartilagem calcificada, levando consigo células progenitoras hematopoiéticas que se diferenciam em células clásticas e reabsorvem parcialmente a cartilagem calcificada. Com os vasos sanguíneos chegam também à região células osteoprogenitoras originárias do periósteo, que proliferam e se diferenciam em osteoblastos. Estes formam camadas contínuas nas superfícies dos tabiques cartilaginosos calcificados e iniciam a síntese da matriz óssea que logo se mineraliza. Forma-se assim, tecido ósseo primário sobre os restos de cartilagem calcificada (KRONENBERG, 2003; OLSEN et al., 2000).

Deve-se observar que em uma determinada região (nos ossos longos entre a epífise e a diáfise) permanecerá um disco de tecido cartilaginoso, denominado placa de crescimento ou disco epifisário, que, através da multiplicação de condrócitos, é responsável pelo crescimento do osso durante sua formação. Seu desaparecimento por ossificação determina a parada do crescimento dos ossos, quando eles atingem seu tamanho máximo (ASZÓDI et al., 2000).

Embora a maioria dos estudos utilize o joelho (tíbia e/ ou fêmur) como modelo de ossificação endocondral, o côndilo em crescimento foi escolhido 
para este estudo por pertencer ao complexo crânio-facial. É classicamente aceito o papel dos componentes da matriz orgânica no processo de biomineralização (LOWENSTAM, 1981), uma vez que as moléculas ali presentes interagem com os íons cálcio dos fluidos extracelulares e com a superfície do cristal em crescimento. Assim, diversos autores têm demonstrado recentemente o papel do ectomesênquima no estabelecimento de estruturas conjuntivas um tanto diferentes daquelas do restante do organismo (revisado em COBOURNE e SHARPE, 2003). Além disso, dependendo de sua origem, os ossos possuem diferentes mecanismos de sinalização e funções (CHUNG et al., 2004).

Os mecanismos envolvidos no processo de biomineralização são resultados da interação de muitos fatores biológicos e físico-químicos. Tendo sido formada a matriz orgânica, os primeiros cristais de mineral são depositados em micro compartimentos formados por vesículas da matriz, que se originam dos osteoblastos. Estas vesículas compõem um microambiente favorável para a precipitação de fosfato de cálcio e para a preservação do mineral nascente, constituindo o que se denomina "fase vesicular" da mineralização. Finalmente, quando as vesículas da matriz estão calcificadas, o processo de mineralização progride para as fibrilas colágenas e para as regiões interfibrilares, constituindo uma etapa que se denomina "fase fibrilar", na qual outros componentes da matriz, denominados não colágenos, são secretados pelos osteoblastos (KATCHBURIAN e ARANA-CHAVEZ, 2004). Uma das características comuns a estas proteínas não-colágenas é 0 abundante conteúdo em aminoácidos-acídicos, que lhes confere alta afinidade pelo cálcio, dando-Ihes a capacidade de regular muitos aspectos da formação mineral, como a nucleação e controle do formato e crescimento do cristal, além da inibição da mineralização. Estas proteínas ligam-se às fibrilas colágenas, dando-Ihes, então, a capacidade de se mineralizarem (DESHPANDE e BENIASH, 2008; KAVUKCUOGLU et al., 2009; NANCl et al., 2008).

Não há dúvidas de que muitas moléculas associadas com 0 desenvolvimento ósseo endocondral estão também presentes durante a ossificação intramembranosa; entretanto, análises aprofundadas revelam diferenças consideráveis nos mecanismos biológicos e bioquímicos de formação, assim como na composição da matriz dos tecidos ósseos formados 
por cada um destes processos (CHUNG et al., 2004; SCOTT e HIGHTOWER, 1991). Van Den Bos et al., 2008 demonstraram haver diferenças na composição protéica da matriz de ossos chatos e longos, enquanto Suttapreyasri et al., 2006 indicaram que o modelo de expressão das proteínas morfogenéticas ósseas (BMPs) é diferente dependendo da origem embriológica do tecido. Além disso, grupos específicos de PGs também mostraram expressão diferenciada nos dois tipos de ossificação (WADDINGTON et al., 2003).

Apesar de terem sido descritas várias propriedades das PGs, suas funções no tecido ósseo ainda são pouco conhecidas. No processo de mineralização na ossificação intramembranosa, por exemplo, foi descrito que as PGs se ligam ao cálcio, inibindo o aparecimento inicial dos cristais de mineral no interior das vesículas da matriz. Posteriormente, há diminuição da quantidade e tamanho destas moléculas associadas à membrana das vesículas (SELA et al., 1992). Entretanto, na ossificação endocondral, os tabiques de cartilagem calcificada funcionam como nucleadoras do mineral da matriz óssea e as vesículas da matriz não estão presentes. Decorin e biglican são PGs altamente expressas na matriz óssea, tendo sido apontadas como participantes no processo de diferenciação dos osteoblastos, além de atuarem regulando a deposição mineral e a morfologia do cristal em crescimento (WADDINGTON et al., 2003).

O conhecimento a respeito de como essas macromoléculas atuariam durante os diferentes tipos de formação óssea poderia auxiliar não somente no entendimento do desenvolvimento normal dos ossos, como também dos processos patológicos que afetam este tecido (ASZÓDI et al., 2000; MANIA et al., 2009).

\subsection{Proteoglicanas}

As PGs são macromoléculas complexas (poliânions) que participam da organização da matriz extracelular e de várias cascatas de sinalização, além de serem capazes de afetar eventos intracelulares, interferindo no comportamento 
celular (HOCKING et al., 1998; SCHAEFER e SCHAEFER, 2009). São constituídas por um eixo protéico que liga-se, covalentemente, a cadeias de glicosaminoglicanas (GAGs). Estas, por sua vez, são carboidratos não ramificados carregados negativamente, altamente hidrofílicos, formados por repetidas unidades de dissacarídeos, que influenciam diretamente nas propriedades físicas das PGs (HARDINGHAM e FOSANG, 1992; GANDHI e MANCERA, 2008). As PGs são de tamanhos e formas diferentes, de modo que apenas a presença da GAG e seu eixo protéico é característica comum a todas as PGs, com exceção do ácido hialurônico, que não possui a proteína central.

Existe uma enorme quantidade de GAGs, devido à grande variação no grau e local de acetilação e sulfatação do grupamento amino, além do tipo de ligação glicosídica e geometria do grupamento carboxílico. Entretanto, de sua estrutura básica, podem ser classificados cinco tipos de cadeias de GAGs: ácido hialurônico, heparan-sulfato, condroitin-sulfato, dermatan-sulfato e queratan-sulfato (LINDE, 1989; SCHAEFER e SCHAEFER, 2009).

Além disso, foram descritos diversos tipos de proteínas formadoras do eixo central das PGs, mas apenas três classes são consideradas, determinadas por sua morfologia. As PGs pequenas são formadas por proteínas globulares com uma ou duas cadeias glicídicas. As PGs longas possuem uma região globular em sua extremidade, com uma extensão polipeptídica linear, sendo que esta apresenta-se ligada a não menos que cinco até não mais de quinze cadeias de GAGs. As PGs muito longas, particularmente aquelas encontradas na cartilagem, têm acima de três regiões globulares ligadas a longas cadeias polipeptídicas (SCOTT, 1988).

Às PGs e seus constituintes GAGs têm sido atribuído importante papel como mediadores na formação dos tecidos mineralizados (WADDINGTON et al., 2003; BONUCCI, 2009). Entretanto, em contraste com a maioria das espécies de PGs encontradas na cartilagem e nos tecidos conjuntivos em geral, as PGs existentes na matriz mineralizada do osso e da dentina pertencem à classe das $\mathrm{PGs}$ pequenas, com somente uma ou duas cadeias $\mathrm{e}$ peso molecular abaixo de $100 \mathrm{kDa}$ (LINDE, 1989). Aparentemente, durante o processo de mineralização, as $P G s$ de maior tamanho seriam degradadas, persistindo as menores (CASTRO e ARANA-CHAVEZ, 1998). 


\subsubsection{Proteoglicanas pequenas ricas em leucina}

As proteoglicanas pequenas ricas em leucina (PPRL) formam uma grande família composta por 17 membros segundo Schaefer e lozzo, 2008. Estes componentes, embora possuam homologia estrutural entre si, se desenvolveram a partir de genes diferentes, adquiriram funções únicas e sofreram um alto grau de sofisticação estrutural. Cinco classes das PPRL são atualmente descritas por esses autores, identificadas de acordo com vários parâmetros, que incluem: sua conservação através da evolução, a presença de domínios ricos em cisteína na região $\mathrm{N}$-terminal, o número de seqüências repetitivas de leucina e sua organização genômica, embora, classicamente, outros autores reconheçam apenas as classes I a III (MCEWAN et al., 2006; NIKITOVIC et al., 2008; KAWASAKI et al., 2009). A rede de sinalização das PPRLs tem sido relacionada ao controle tecidual da morfogênese, crescimento neoplásico e imunidade inata, entre outras funções.

Classe I - Esse grupo inclui decorin (KRUSIUS e RUOSLAHTI, 1986) e biglican (FISHER et al., 1989). Estas PGs contém um domínio N-terminal que, usualmente, é o lugar onde se ligam um (decorin) ou dois (biglican) canais laterais de condroitin/dermatan-sulfato, responsáveis por pronunciadas propriedades polianiônicas. A característica mais saliente destas PGs é a presença de dez repetições de leucina, ladeada por regiões ricas em cisteína. Atualmente a asporina tem sido incluída neste grupo, embora ela não seja conhecida como uma proteoglicana clássica.

Decorin e biglican têm sido identificados em muitos tecidos conjuntivos. Ambos são altamente expressos na matriz óssea e, atualmente, existem evidências substanciais demonstrando que estes PPRL influenciam a diferenciação das células ósseas e sua atividade proliferativa (BIANCO et al., 1990; HAUSSER et al., 1994; TAKEUCHI et al., 1994; MARKMANN et al., 2000). Em adição, estas PPRL têm sido implicadas na regulação da deposição mineral e morfologia do cristal de hidroxiapatita durante a fase de mineralização da matriz óssea; enquanto o decorin tem ainda sido mencionado como participante da formação da matriz orgânica (SUGARS et al., 2003). Tem 
sido sugerido ainda que a natureza da cadeia de GAG (condroitin ou dermatansulfato) conjugada à proteína e o momento de sua expressão poderiam determinar as funções do biglican e decorin durante a formação óssea (WADDINGTON et al., 2003).

Classe II - Este grupo compreende 5 PGs, que podem ser divididas em 3 subfamílias distintas: fibromodulina (OLDBERG et al., 1989) e lumican (BLOCHBERGER et al., 1992; FUNDERBURGH et al., 1993) constituem a primeira subfamília; queratocan (CORPUZ et al., 1996) e PRELP (BENGTSSON et al., 1995) a segunda, enquanto a osteoaderina (SOMMARIN et al., 1998) constitui uma subfamília distinta dos outros membros da classe II. Todos eles são codificados por apenas três éxons, com um extenso éxon central codificando quase todas as onze repetições de leucina. Estas PGs possuem uma região idêntica rica em cisteína posicionada imediatamente antes das onze repetições ricas em leucina. Em contraste com a região $\mathrm{N}$ terminal do decorin e biglican, os membros da classe II contém grupos de resíduos sulfatados de tirosina, que contribuiriam para a sua natureza polianiônica, e são primariamente substituídos com canais queratan-sulfato e polilactosamina (SCHAEFER e IOZZO, 2008).

Classe III- Epifican, Opticina e mimecan/osteoglicina são os três membros desta classe. Estas PGs podem ser distinguidas por um região única rica em cisteína e pela presença de apenas seis repetições de leucina.

Classes IV e V - Propostas por Schaefer e lozzo, 2008, seriam compostas pela condreoaderina, nictalopina e tsukushi (classe IV) e por podocan e podocan- like I (classe V).

A rede de sinalização das PPRLs tem sido relacionada ao controle tecidual da morfogênese, crescimento neoplásico e imunidade inata, entre outras funções.

A versatilidade molecular das PGs thes confere a habilidade de estabelecer interações célula- célula e célula- matriz extracelular. Pouco é conhecido sobre o destino destes constituintes da matriz durante os complexos processos de ossificação, embora se saiba que a distribuição das PGs é altamente dinâmica durante estes processos, levando à mudança da natureza 
da matriz (ERLEBACHER et al., 1995). Enquanto na ossificação intramembranosa os osteoblastos secretam as PGs como parte da matriz óssea definitiva, na ossificação endocondral há remoção da matriz cartilaginosa pré-existente (com suas PGs características) e deposição de uma nova matriz extracelular, sugerindo que haja diferenças relacionadas aos constituintes proteoglicanos da matriz durante os dois tipos de ossificação. Sendo assim, o papel biológico e funcional das PPRL é variável de acordo com o tipo de PG que está sendo expresso em cada fase de desenvolvimento (WADDINGTON et al., 2003). Enquanto a função das $P G s$ decorin e biglican durante a formação óssea tem sido amplamente avaliada, pouco se conhece sobre o papel específico de outras PPRLs, dentre elas a osteoaderina (OSAD). Sua presença já foi detectada em osteoblastos, odontoblastos e ameloblastos de ratos (BUCHAILLE et al., 2000), odontoblastos humanos (LUCCHINI et al., 2002) além de ter sido localizada extracelularmente no osso alveolar, pré-dentina e matriz de esmalte de ratos e camundongos (COUBLE et al., 2004)

\subsubsection{Osteoaderina}

A osteoaderina (OSAD) é uma PG queratan-sulfato de adesão celular, pertencente à família das PPRL, isolada de osso bovino mineralizado (WENDEL et al., 1998) e subseqüentemente clonada e sequenciada (SOMMARIN et al., 1998). A característica predominante da estrutura primária da OSAD é uma região central consistindo de 11 repetições ricas em leucina, com uma extensão de 20 a 30 resíduos, além da presença exclusiva de um grande domínio C-terminal, que, por ser rico em ácido aspártico e ácido glutâmico, torna a proteína altamente acídica, facilitando a ligação com os cristais de hidroxiapatita (WENDEL et al., 1998; ZHOU, 2007). A literatura acerca da presença de OSAD durante a ossificação intramembranosa ou endocondral é escassa, e seu papel nestes processos pouco compreendido.

Baseado em resultados obtidos de experimentos in vitro, a proteína mostrou ter propriedades de adesão celular altamente dependente de cátions, promovendo a ligação de osteoblastos via integrina $\alpha v \beta 3$. Nestes estudos, os 
autores sugeriram que a OSAD fosse específica do osso, tendo papéis diferentes na regulação da mineralização e adesão celular (WENDEL et al., 1998; SOMMARIN et al., 1998). Entretanto, posteriormente, a OSAD foi identificada em outros tecidos e células, como no estudo que demonstra seu papel na adesividade entre odontoblastos e entre estas células e sua matriz circundante - pré-dentina, dentina e polpa (LUCCHINI et al., 2004). Buchaille et al., 2000, usando hibridização in situ, relataram a expressão de RNAm de OSAD durante o desenvolvimento de tecidos dentários humanos. Os primeiros sinais de detecção da OSAD apareceram nos odontoblastos polarizados, aumentando nas células secretoras e maduras, respectivamente. Além disso, surpreendentemente, um modelo de expressão similar foi por eles observado na camada de ameloblastos, os levando a sugerir uma localização generalizada para a OSAD nas matrizes mineralizadas. Em outros estudos, a OSAD foi localizada, através de imunomarcação e hibridização in situ, na matriz da pré-dentina, dentina mineralizada, cemento e osso alveolar circundante, tendo sido altamente expressa nas fases iniciais de formação da coroa dental e da pré- dentina e em toda a camada de odontoblastos;, indicando que a OSAD pode estar associada com as fibrilas de colágeno, tendo um papel importante durante o desenvolvimento dentário e a organização dos tecidos mineralizados (PETERSSON et al., 2003; COUBLE et al., 2004). Para testar a hipótese de que a OSAD exerce um papel na mineralização em um modelo in vivo, amostras de tíbia (metáfise e diáfise) e calvária de ratos foram examinadas através de imunohistoquímica, a fim de localizar a OSAD ultraestruturalmente. Em adição às análises qualitativas, mensurações quantitativas da densidade de marcadores para OSAD também foram feitas neste estudo. $A$ imunomarcação para OSAD foi localizada na matriz do osso mineralizado, com alta concentração de marcadores na borda entre o osso e remanescentes de cartilagem nas trabéculas metafisárias. A marcação intracelular foi baixa e não foi observada acumulação sistêmica de OSAD na interface matriz-célula. $O$ padrão de distribuição observado para OSAD foi extremamente parecido com aquele da sialoproteína óssea (BSP), confirmado por dupla marcação. Os resultados deste estudo foram então condizentes com um papel da OSAD na mineralização, supondo ainda que a BSP seria nucleadora dos cristais de 
hidroxiapatita e a OSAD trabalharia em conjunto com a BSP na regulação da nucleação (RAMSTAD et al., 2003).

Recentemente, foram feitas análises sobre a atuação da OSAD no processo de diferenciação e maturação dos osteoblastos. Rehn et al., 2006 chegaram à conclusão que, a OSAD regulada por TGF - $\beta 1$ e BMP-2, funcionaria como um marcador de osteoblastos diferenciados $e$, posteriormente, Rehn et al., 2008, notaram que a maturação dos osteoblastos em cultura foi aumentada pela "super expressão" de OSAD.

\subsection{Imunocitoquímica e processamento com microondas}

A imunocitoquímica ultra-estrutural com ouro coloidal é um método bastante eficiente que tem sido aplicado com sucesso na identificação de proteínas para o estudo da sua presença e distribuição nos tecidos (BENDAYAN, 1986). Entretanto, para se obter resultados fidedignos em experimentos de imunocitoquímica, alguns critérios importantes devem ser considerados: a manutenção da antigenicidade da proteína, a rápida imobilização do antígeno, a preservação da estrutura celular, a acessibilidade aos antígenos e a paralisação das reações enzimáticas (HIPPE-SANWALD, 1993). Os métodos convencionalmente utilizados durante o processamento de amostras para análise em microscopia eletrônica envolvem fixadores químicos em soluções aquosas seguido pela desidratação com solventes orgânicos e posterior inclusão em resinas plásticas. Estes procedimentos, apesar de fornecerem, geralmente, boa preservação estrutural, são altamente prejudiciais para a antigenicidade. Macromoléculas altamente hidratadas como as proteoglicanas, por exemplo, são extremamente difíceis de se preservar adequadamente através da fixação química e desidratação convencional. Por esta razão, algumas alternativas têm sido utilizadas na preparação de amostras biológicas, como a irradiação por microondas.

A movimentação das moléculas de água, provocada pela irradiação com microondas, aumenta a taxa de penetração de substâncias químicas nos 
tecidos, acelerando o processamento dos espécimes e melhorando, assim, a preservação dos mesmos (MASSA e ARANA-CHAVEZ, 2000). O glutaraldeído, por exemplo, pode ser usado em menores concentrações, fornecendo boa preservação do tecido e superior preservação antigênica. RANGELL e KELLER (2000) aplicaram a tecnologia da irradiação por microondas no processamento e imunomarcação de materiais embebidos em resina acrílica e crioseccionados, observando que o tempo de processamento foi diminuído consideravelmente, sem comprometer a qualidade de preservação ultraestrutural e a especificidade da reação. Apesar disto, os efeitos do aquecimento para os antígenos são complexos e vários tipos de antígenos podem ser afetados de maneiras diferentes, dependendo da sua localização intracelular e até das estruturas secundárias e terciárias do antígeno. Por isto, esta imunorreatividade foi testada em proteínas não colágenas dos tecidos mineralizados, mostrando que a irradiação com microondas também proporciona, no caso destas proteínas, boa qualidade na preservação dos tecidos, além de uma adicional recuperação antigênica, possibilitando sua detecção, mesmo que elas estejam presentes em pequenas quantidades (ARANA-CHAVEZ e NANCI, 2001; NANCl et al., 2008). 
3 PROPOSIÇÃO 
O objetivo deste estudo foi fazer uma análise da presença de uma PG pequena rica em leucina, a osteoaderina, durante os processos de ossificação intramembranosa e ossificação endocondral, respectivamente no osso parietal e no côndilo da mandíbula de ratos. A distribuição dessa PG foi avaliada durante os estágios iniciais de desenvolvimento ósseo através de imunocitoquímica de alta-resolução, associada à ao processamento com microondas, com o intuito de melhorar a preservação das PGs nos tecidos. Além disso, o Western Blotting foi utilizado para fazer uma análise semiquantitativa da presença de OSAD nos diferentes períodos de desenvolvimento do osso. 
4 MATERIAIS E MÉTODOS 


\subsection{Material em estudo}

Para o estudo da ossificação intramembranosa foi utilizado osso parietal de fetos de ratos Wistar (Rattus norvegicus albinus) com 17, 18 e 21 dias. 0 osso parietal dos animais com estas idades (de 17 dias v.i.u. até o nascimento) é um modelo classicamente utilizado para o estudo deste tipo de ossificação. Nele, é possível encontrar tecido ósseo nas fases iniciais da osteogênese, desde a formação das primeiras trabéculas de osso primário até o início da remodelação, que levará a formação do osso secundário ou lamelar (ARANACHAVEZ et al., 1995).

Para o estudo da ossificação endocondral foi utilizado o côndilo da mandíbula de ratos com 30 dias de vida. O processo de ossificação endocondral começa na região da mandíbula ao redor do $15^{\circ}$ dia de vida e permanece até aproximadamente os 60 dias (COPRAY et al., 1988). Os primeiros dias, entretanto, são caracterizados por uma proliferação mais acentuada da zona dos condrócitos em multiplicação, a qual se torna menos intensa a partir do $28^{\circ}$ dia. Assim, aos 30 dias de vida a constituição do côndilo mandibular está bem estabelecida, tornando possível a análise dos componentes da matriz neste tipo de ossificação, tanto da cartilagem em calcificação, como da matriz de osso primário que é depositada sobre os tabiques de cartilagem calcificada (MARCHI et al., 1991).

\subsection{Obtenção e processamento dos espécimes}

Para o acasalamento, fêmeas e machos, na proporção de 1:1, foram mantidos juntos por uma noite e separados pela manhã, ocasião em que, com o auxílio de cotonetes de algodão, foram feitos esfregaços vaginais para a verificação da presença ou não de espermatozóides. Os esfregaços, após serem fixados em álcool-éter, foram corados pela técnica de Shorr (1941) e examinados ao microscópio de luz. A presença de espermatozóides nos esfregaços estabeleceu o primeiro dia de gestação. 
Fêmeas no $17^{\circ}, 18^{\circ}$ e $21^{\circ}$ dias de gestação foram anestesiadas com solução aquosa a $2 \%$ de cloridrato de 2-(2,6-xilidino)-5,6-dihidro-4-H-1,3tiazina (Rompun ${ }^{\circledR}$ ) diluído 1: 1 em ketamina (Francotar $\left.{ }^{\circledR}\right)$, via intramuscular, na dosagem de $1,0 \mathrm{ml} / \mathrm{Kg}$ de peso corporal e os fetos rapidamente retirados e sacrificados por decapitação. Suas cabeças foram separadas cirurgicamente e imediatamente imersas em uma solução fixadora (Imunocitoquímica) ou em nitrogênio líquido (Western Blotting).

As calotas cranianas processadas para microscopia de luz foram removidas e imersas em $0,1 \%$ de glutaraldeído $+4 \%$ de formaldeído (preparado a partir de paraformaldeído) em tampão cacodilato pH 7,4 a 0,1 M. Os espécimes foram então colocados em um béquer contendo $40 \mathrm{ml}$ de solução fixadora a temperatura ambiente, tendo sido este subseqüentemente posicionado no centro de um recipiente de vidro de $20 \times 20 \mathrm{~cm}$ contendo gelo picado e, finalmente, colocado em um forno de microondas Pelco 3440 (Ted Pella, Redding, CA. USA). Um termômetro imerso na solução fixadora durante a operação do forno foi utilizado para monitorar a temperatura da mesma que não deve ser maior que $37^{\circ} \mathrm{C}$. Os espécimes foram expostos a 3 ciclos de 5 minutos a 100\% de potência. Após a irradiação de microondas, foram imersos em nova solução fixadora e permaneceram overnight a $4{ }^{\circ} \mathrm{C}$ (MASSA E ARANA-CHAVEZ, 2000).

Os ratos com 30 dias de vida foram anestesiados com a mesma solução descrita anteriormente. Em seguida suas mandíbulas foram removidas e a região condilar foi rapidamente separada e imersa no mesmo fixador já descrito, passando também pelo processamento com microondas.

Após a irradiação, todos os espécimes foram transferidos para uma solução nova do mesmo fixador e deixados por 4 horas, tendo sido então lavados por mais uma hora na mesma solução tampão. Todos os côndilos removidos dos ratos e parte das calotas extraídas dos fetos foram descalcificados em EDTA a $4,13 \%$ durante aproximadamente quinze dias, seguida de lavagem em água corrente durante 24 horas e desidratação em concentrações crescentes de etanol, tendo sido infiltrados à temperatura ambiente em misturas crescentes de resina LR White (London Resin Company Ltda., England) diluída em etanol e finalmente em resina pura, na qual foram 
incluídos no dia seguinte, utilizando-se cápsulas de gelatina, e deixados para polimerizar em estufa a $60 \stackrel{\circ}{\mathrm{C}}$ por 72 horas.

Os blocos obtidos foram trimados e cortados em um micrótomo HM 360, Zeiss, com a utilização de facas de vidro feitas com um "knife maker" LKB 7800-B. Os cortes semi-finos foram montados em lâminas de vidro, corados com solução alcoólica de azul de toluidina a $0,25 \%$ e observados ao microscópio de luz.

\subsection{Imunocitoquímica pós-inclusão com ouro-coloidal}

As amostras selecionadas para imunocitoquímica foram fixadas em glutaraldeído a $0,1 \%$ + formaldeído a $4 \%$ (preparado do paraformaldeído), tendo todo o restante de seu processamento idêntico ao descrito para a coloração com azul de Toluidina. Depois de selecionada a área em microscópio de luz, os blocos foram novamente trimados, para a obtenção de cortes ultrafinos, em um ultramicrótomo Leica, Ultracut $R$, com a utilização de navalha de diamante Diatome ou Drukker. Os cortes foram coletados em telas de níquel de 200 "meshes" cobertas com película de parlódion e, posteriormente, incubados com o anticorpo específico.

Os cortes ultra-finos foram submetidos ao processo de incubação, para a marcação do anticorpo de coelho ANTI-OSTEOADERINA (OSAD) de rato (COUBLE et al., 2004).

As telas foram colocadas em uma solução bloqueadora de leite desnatado a $5 \%$ em PBS $0,01 \mathrm{M}(\mathrm{pH} 7,2)$, durante 20 minutos. Posteriormente, os espécimes foram incubados com o anticorpo ANTI-OSTEOADERINA diluído 1:50 em PBS $0,01 \mathrm{M} \mathrm{pH} \mathrm{7,2,} \mathrm{durante} 12$ horas. Findo este tempo, foi realizada a lavagem com PBS $0,01 \mathrm{M}(\mathrm{pH} 7,2)$, durante 15 minutos. Os espécimes foram tratados com solução bloqueadora de BSA a $1 \%$ antes de serem incubados com proteína A-ouro diluída 1:5 em PBS 0,01 M (pH 7,2), durante 2 horas. Finalmente, as telas foram lavadas com PBS $0,01 \mathrm{M}(\mathrm{pH} 7,2)$ e em seguida com água destilada por 15 minutos. 
Como controle negativo das imunomarcações, o anticorpo foi substituído, em algumas reações, por soro pré-imune, enquanto outras telas foram incubadas somente com o complexo proteína A-ouro coloidal, sem serem expostas ao anticorpo.

Todos os cortes, tanto os processados para análise morfológica, como os provenientes dos ensaios imunocitoquímicos, foram contrastados em uma solução alcoólica de acetato de uranila a $2 \%$ por 10 minutos e, em seguida, com citrato de chumbo a $0,5 \%$ por mais 5 minutos. Posteriormente foram examinados em microscópio eletrônico de transmissão Jeol 1010, operado a $80 \mathrm{Kv}$.

\subsection{Western Blotting}

Calotas cranianas de animais com 17, 18 e 21 dias de v. i. u. foram removidas cirurgicamente e posicionadas em stubs de alumínio, tendo sido o conjunto imerso em nitrogênio líquido. Em seguida, foram transferidos para tubos eppendorf contendo nitrogênio líquido, onde ficaram armazenados.

Em seguida, aproximadamente 15 calotas foram trituradas até se reduzirem a pó, e então diluídas em $1 \mathrm{ml}$ de tampão de lise contendo $\mathrm{KCl} 100$ $\mathrm{mM}+$ Hepes $10 \mathrm{mM}+\mathrm{MgCl} 3 \mathrm{mM}+$ EDTA $5 \mathrm{mM}+\mathrm{DTT} 1 \mathrm{mM}+\mathrm{SDS}$ a $10 \% \mathrm{e}$ Glicerol a $10 \%$ adicionados à $10 \mu \mathrm{L}$ de Inibidor de Protease.

O lisado foi submetido à agitação sônica por 1 minuto e centrifugado à $10000 \mathrm{rpm}$ por 10 minutos a $4^{\circ} \mathrm{C}$, tendo sido o sobrenadante aliquotado e estocado a $-80 \stackrel{\circ}{\circ}$. As proteínas foram quantificadas com o kit BCA Protein Assay Kit da Pierce (Reagente B + Reagente A 1:50 + $20 \mu \mathrm{l}$ de amostra, analisados em elisa). A quantificação foi realizada em um aparelho de ELISA (ELX 800 Bio-Tek Instruments, Inc.) em placas de 96 poços contendo $200 \mu \mathrm{l}$ de BCA, além de $20 \mu \mathrm{l}$ de cada lisado ou $20 \mu \mathrm{l}$ de BSA, nas concentrações indicadas pelo fabricante, para realização da curva padrão. A leitura foi realizada com filtro de $550 \mathrm{~nm}$. 
As alíquotas do sobrenadante, contendo $50 \mu \mathrm{g}$ de proteína total, foram misturadas com tampão de amostra para concentração final de 1X. Em seguida, foram fervidas por 5 minutos e então submetidas a SDS-PAGE, sendo feita eletroforese a $100 \mathrm{~V}$ por 180 minutos, em gel de acrilamida a $12 \%$. $\mathrm{O}$ padrão de peso molecular utilizado foi o Full range Rainbow (Amersham).

Gel $12 \%$ acrilamida com SDS (10X10 cm)

\begin{tabular}{|c|c|c|}
\hline & $\begin{array}{c}\text { Gel de Separação } \\
\mathbf{1 2 \%} \\
\text { (Total 15 ml) }\end{array}$ & $\begin{array}{c}\text { Gel Empilhamento 5\% } \\
\text { (Total 3 ml) }\end{array}$ \\
\hline $\mathrm{H}_{2} \mathrm{O}$ & $\mathbf{4 , 9}$ & 2,7 \\
\hline $\begin{array}{c}\text { Acrilamida/Bisacrilamida } \\
30 \%\end{array}$ & 6,0 & 0,67 \\
\hline $1,5 \mathrm{M}$ Tris (pH8.8) & 3,8 & --- \\
\hline $1,0 \mathrm{M}$ Tris (pH 6.8) & --- & 0,38 \\
\hline SDS 10\% & 0,15 & 0,03 \\
\hline Persulfato de amônio & 0,15 & 0,03 \\
\hline $10 \%$ & 0,006 & 0,003 \\
\hline Temed & & \\
\hline
\end{tabular}

A transferência das proteínas para a membrana de nitrocelulose foi feita por eletro-transferência semi-seca em aparelho especial (Amersham minutosi VE). Com o tampão de transferência (250 mM Tris-Base; 1,92 mM Glicina, 20\% Metanol; pH 8,3) utilizado como recomendado pelo fabricante. A transferência foi realizada com $30 \mathrm{~V}$ por 180 minutos. Após a transferência, a membrana foi submetida à fase de bloqueio ou lavada e seca para posterior reação. 
Para a imunoreação, foi feito bloqueio dos sítios inespecíficos com $5 \%$ de leite em pó desnatado em TTBS, por 1hora em temperatura ambiente, sob agitação. Em seguida, a solução de bloqueio foi removida lavando-se a membrana com TTBS e TBS. A membrana foi incubada overnight a $4{ }^{\circ} \mathrm{C}$ com os anticorpos anti- OSAD (1:500; gentilmente cedido pela Dr. Françoise Bleicher, Universidade de Lyon, França) e $\beta$ - actina (1:5000; Santa Cruz Biotechnology, Santa Cruz, CA) . Seguiram duas lavagens com TTBS para remoção do anticorpo não-absorvido e duas lavagens com TBS sob agitação e à temperatura ambiente. Depois da incubação por 1 hora com anticorpo secundário (peroxidase-linked anti-rabbit IgG 1:1000 Amersham Pharmacia Biotech, Aylesbury, UK) diluído em solução de bloqueio, a imunoreatividade foi detectada através do kit ECL da Amersham, seguindo orientações do fabricante. 
5 RESULTADOS 
Os espécimes analisados mostraram tecidos ósseos em vários estágios de formação, tendo sido observadas calvárias de fetos de ratos com 17, 18 e 21 dias v.i.u., apresentando desde a fase inicial de secreção da matriz óssea até a completa progressão da mineralização, passando por diferentes etapas da deposição de mineral. O osso da região condilar foi estudado apenas em ratos com 30 dias de vida, pois, neste período, a constituição do côndilo mandibular está bem estabelecida, tornando possível a análise dos componentes da matriz em diversas fases da ossificação endocondral, desde a cartilagem em calcificação até a matriz de osso primário que é depositada sobre os tabiques de cartilagem calcificada.

Através da análise morfológica do osso parietal dos fetos, foi possível visualizar a camada de tecido ectomesenquimal indiferenciado que circunda as células osteogênicas e os osteoblastos já diferenciados, estes últimos se organizando em fila para dar início à secreção das moléculas da matriz orgânica do futuro osso. Em regiões em que a fase de formação óssea está mais adiantada, osteócitos aprisionados na matriz extracelular calcificada podem ser observados. No côndilo da mandíbula, várias fases da formação óssea endocondral podem ser visualizadas em um mesmo corte, desde as zonas de hipertrofia e morte dos condrócitos, onde restam tabiques de cartilagem calcificada, até as regiões de invasão por capilares e células indiferenciadas provenientes do mesênquima adjacente que lavam à formação de trabéculas ósseas sobre o molde cartilaginoso (Fig. 1 A-C).

A análise imunocitoquímica mostrou o mesmo modelo de expressão para a OSAD, tanto na ossificação intramembranosa quanto na endocondral: poucas partículas de ouro foram vistas uniformemente distribuídas no citoplasma dos osteoblastos e na matriz quando a fase fibrilar de mineralização começou.

Examinando as calvárias dos fetos em cortes ultrafinos, observou-se a presença das vesículas da matriz como sinalizadoras do processo inicial de mineralização. Algumas delas foram vistas ainda não mineralizadas, enquanto outras continham finos cristais de mineral em seu interior.

Nestas áreas, em que as vesículas da matriz já formavam um microambiente favorável à precipitação de fosfato de cálcio, a imunomarcação para OSAD esteve ausente (Fig. 2). 


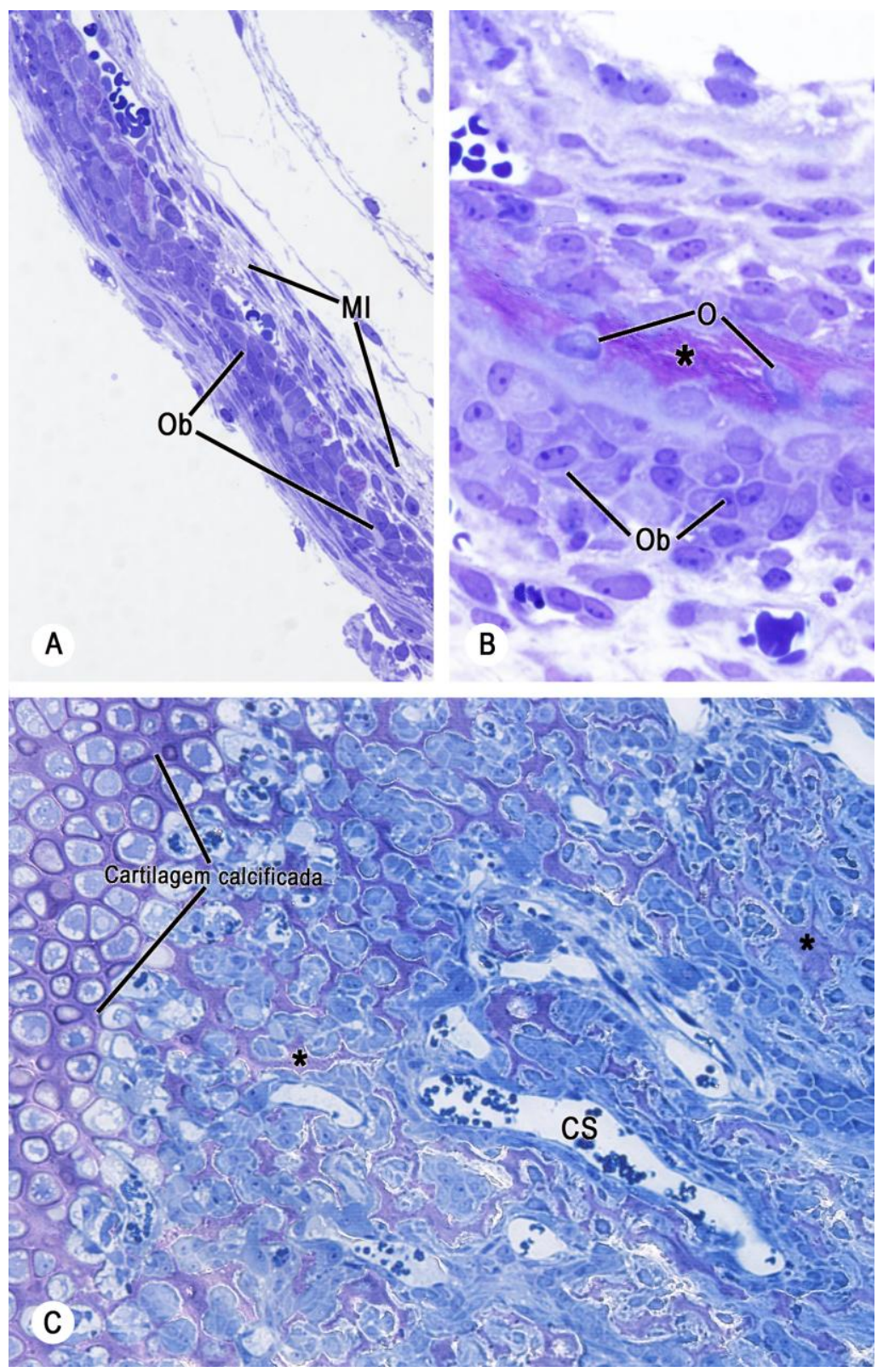

Figura 1- OSSIFICAÇÃO INTRAMEMBRANOSA E ENDOCONDRAL. AFotomicrografia de osso parietal de embrião de rato com 18 dias de vida intra- uterina, apresentando fase inicial da ossificação intramembranosa, onde observam-se osteoblastos diferenciados (Ob), circundados por tecido mesenquimal indiferenciado (MI). (40 X). BFotomicrografia em maior aumento do mesmo espécime mostrado em a, em região que apresenta fase mais avançada do processo de ossificação, quando é possível a visualização de matriz óssea mineralizada (asterisco), osteócitos sendo aprisionados nesta matriz (O), além dos osteoblastos secretores (Ob).(100 X) C- Fotomicrografia de côndilo mandibular de rato com 30 dias de vida, apresentando fases diversas da ossificação endocondral, desde a calcificação do molde cartilaginoso (cartilagem calcificada), passando pela invasão por capilares sanguíneos (CS) e chegada de células osteoprogenitoras, até a formação das primeiras trabéculas ósseas mineralizadas (asteriscos). $(220 \mathrm{X})$. 


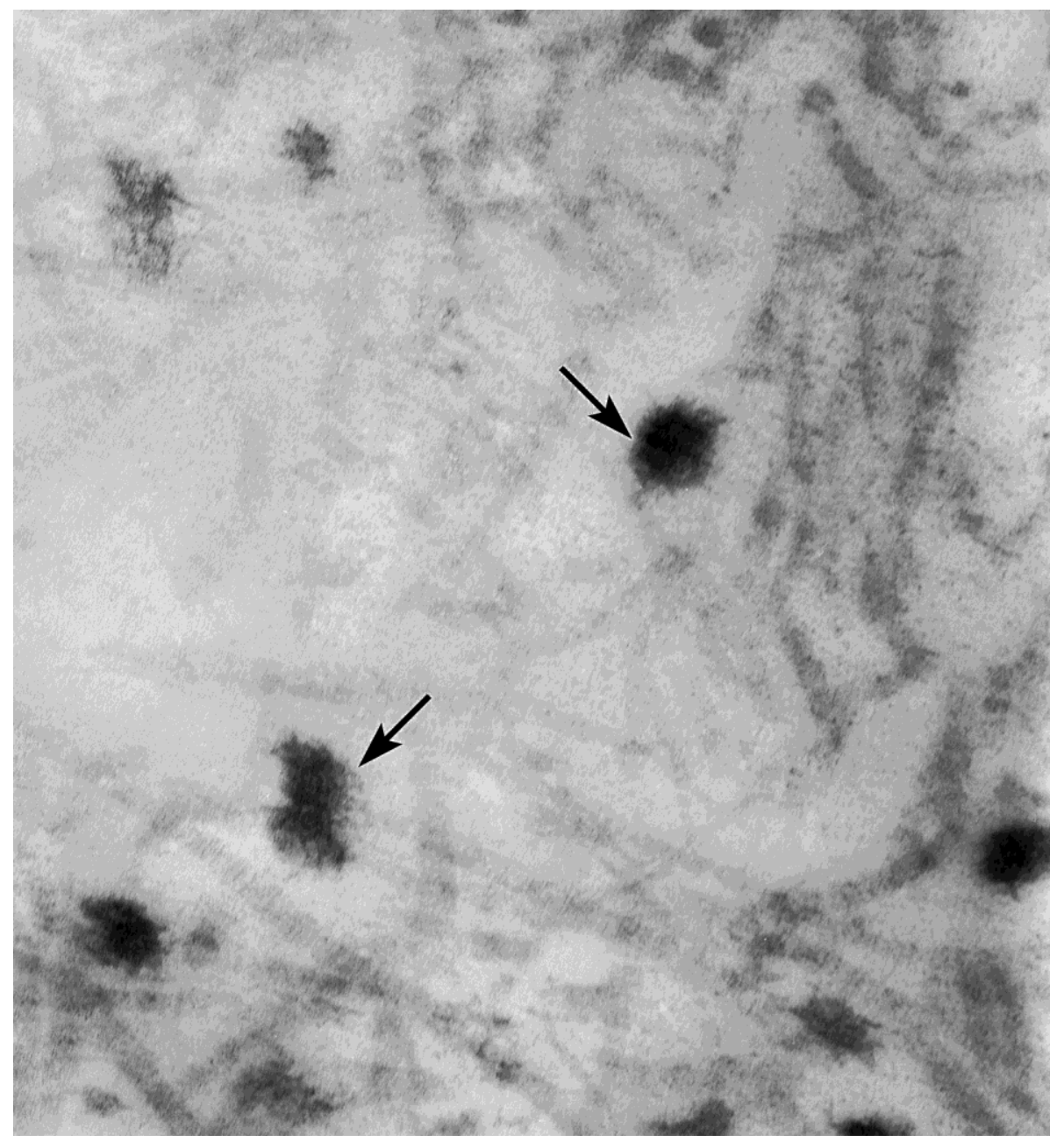

Figura 2- IMUNODETECÇÃO DE OSTEOADERINA. Micrografia eletrônica mostrando a presença de vesículas de matriz (setas) na fase inicial de mineralização da ossificação intramembranosa em calvária de embrião de rato, onde nenhuma marcação foi detectada. $60.000 \mathrm{X}$. 
À medida que os cristais de mineral rompem os limites das vesículas e progridem para as fibrilas colágenas e para as regiões interfibrilares, a marcação para a OSAD pode ser discretamente notada, sendo visível também no citoplasma dos osteoblastos adjacentes a estas regiões (Fig. 3)

$\mathrm{Na}$ fase fibrilar de mineralização, o espaço existente entre as moléculas de fibrilas colágenas é o primeiro a receber a deposição dos cristais de mineral. Neste estágio, as partículas de ouro foram vistas em algumas regiões do citoplasma dos osteoblastos, assim como no osteóide, porção ainda não mineralizada da matriz óssea. $\mathrm{Na}$ região da matriz mineralizada, a imunodetecção foi mais evidente, embora não tenha sido intensa, determinando um padrão de marcação para esta proteoglicana, uma vez que este aspecto se repetiu em todos os espécimes estudados (Fig. 4 A).

Nas amostras descalcificadas antes da inclusão, a imunodetecção para OSAD não foi afetada por tal procedimento, pois na análise imunocitoquímica deste material a marcação para a OSAD se mostrou muito semelhante àquela notada no material não desmineralizado, estando ausente nas regiões de vesículas da matriz (Fig. 5) e se espalhando discretamente em torno destas, quando os cristais de mineral cresceram (Fig. 4 B).

$\mathrm{Na}$ porção intracitoplasmática dos osteoblastos secretores pode-se observar uma distribuição igualmente fraca e homogênea, tendo sido a especificidade da reação comprovada pela ausência de partículas de ouro nas mitocôndrias, que funcionaram como controle negativo (Fig. 6).

$\mathrm{Na}$ análise imunocitoquímica dos cortes de côndilo mandibular, a imunodetecção de OSAD coincidiu com os primeiros sinais de mineralização, uma vez que na zona de ossificação da formação óssea endocondral não há presença de vesículas da matriz e a mineralização ocorre por nucleação heterogênea a partir dos tabiques calcificados de cartilagem, se iniciando já na fase fibrilar. Nestes cortes, a especificidade da reação pode ser verificada novamente, pois somente a matriz óssea apresentou positividade para a marcação para OSAD; a matriz cartilaginosa esteve sempre livre de marcação (Fig. 7A, B e Fig. 8). 

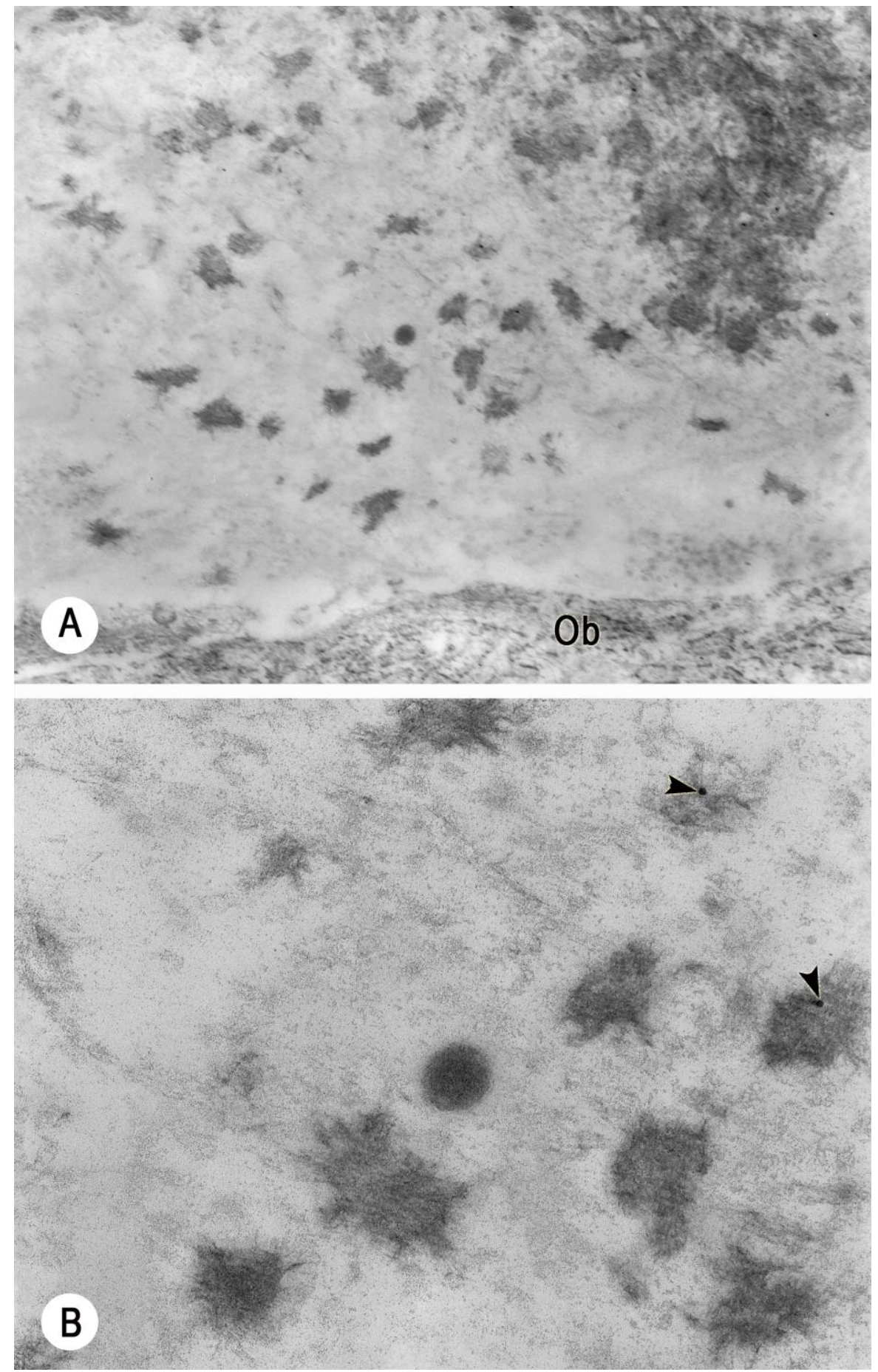

Figura 3- IMUNODETECÇÃO DE OSTEOADERINA. Micrografias eletrônicas mostrando avanço da mineralização durante a ossificação intramembranosa. A- Na porção inferior é mostrado parte de um osteoblasto $(\mathrm{Ob})$. No centro e à direita pode-se notar uma progressão da fase vesicular de mineralização e início da fase fibrilar, respectivamente.15.000X. B- Maior aumento da região central da figura anterior, em que os cristais de mineral começam a extrapolar os limites das vesículas da matriz e as primeiras partículas de ouro aparecem (cabeças de setas). 50.000X. 

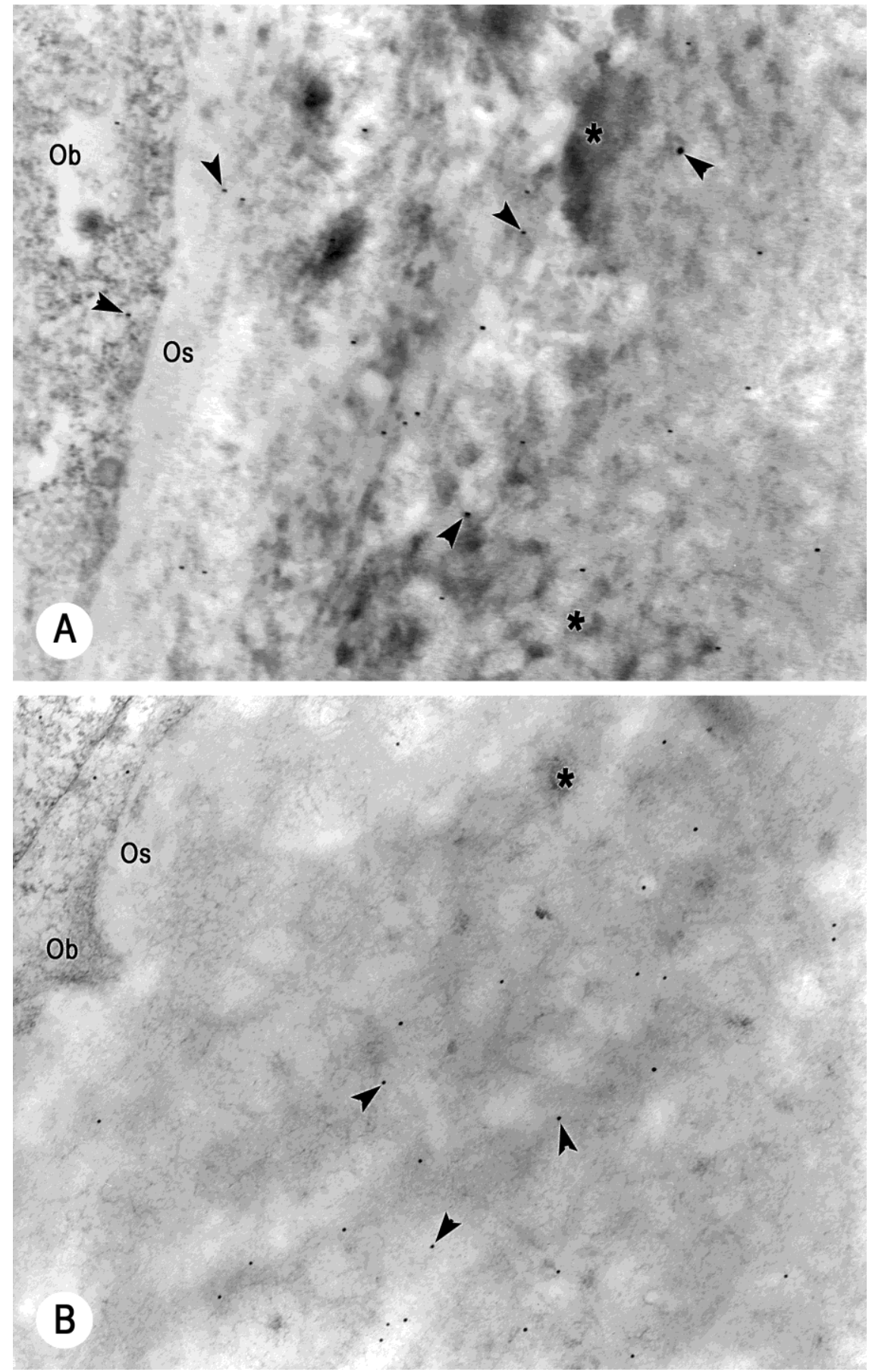

Figura 4- IMUNODETECÇÃO DE OSTEOADERINA. Micrografias eletrônicas da fase fibrilar de mineralização em ossificação intramembranosa. A- A matriz mineral (asterisco) exibe marcação homogênea e mais evidente do que aquela observada no estágio anterior. Note que no osteoblasto (Ob) adjacente, assim como no osteóide (Os), há detecção de poucas partículas de ouro (cabeças de setas). 25.000X. B- Região similar à figura anterior de um espécime que foi desmineralizado durante o processamento. É possível observar que a imunodetecção não foi afetada pelo processo de desmineralização, uma vez que a imunomarcação se apresenta semelhante à daquela figura. Ob, osteoblasto; Os, osteóide. 25.000X. 


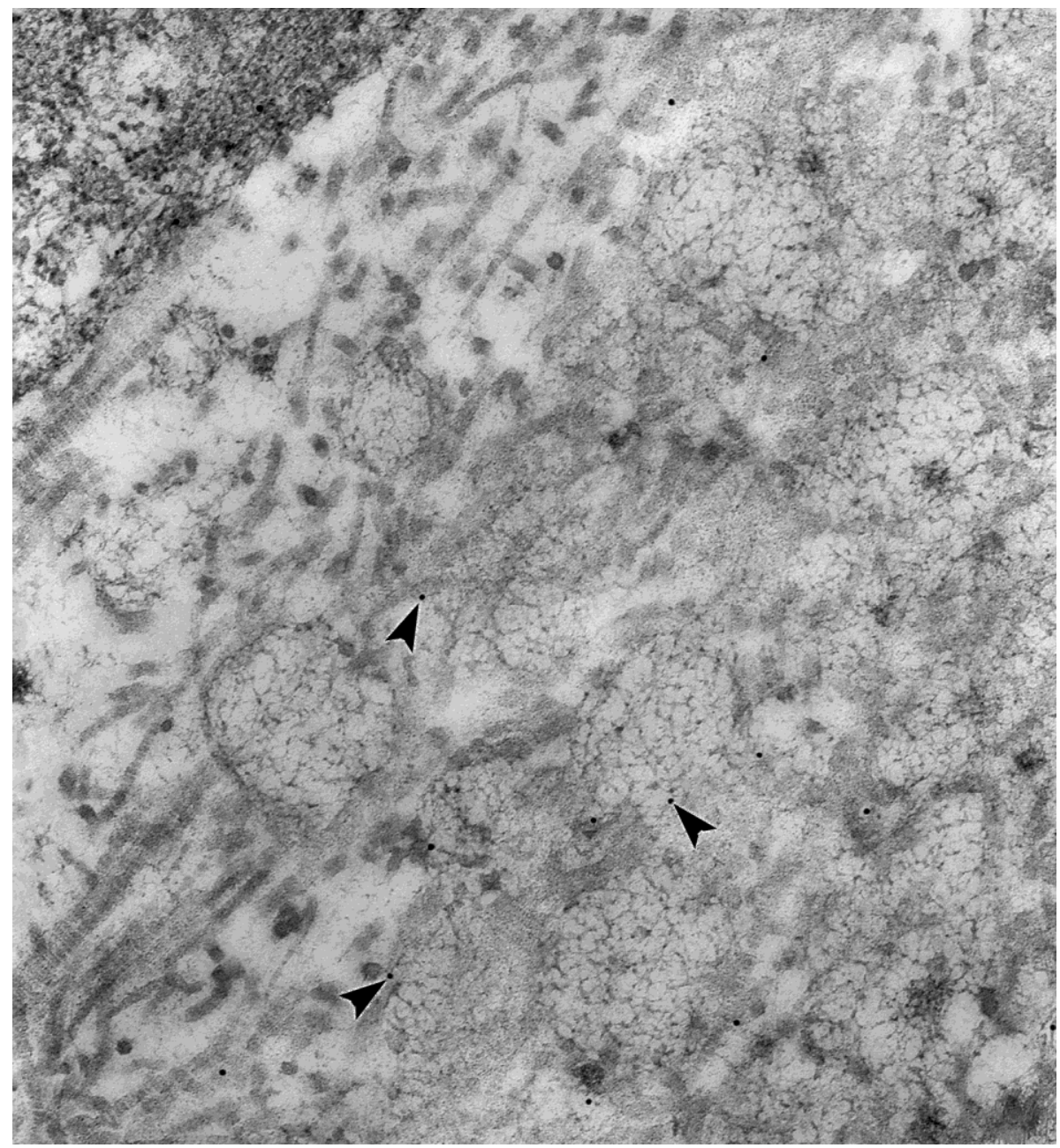

Figura 5- IMUNODETECÇÃO DE OSTEOADERINA. Micrografia eletrônica mostrando marcação para OSAD na fase fibrilar de mineralização em calvária de rato descalcificada. Entre os glóbulos de mineral observa-se fraca imunorreatividade (cabeças de setas).30.000X. 


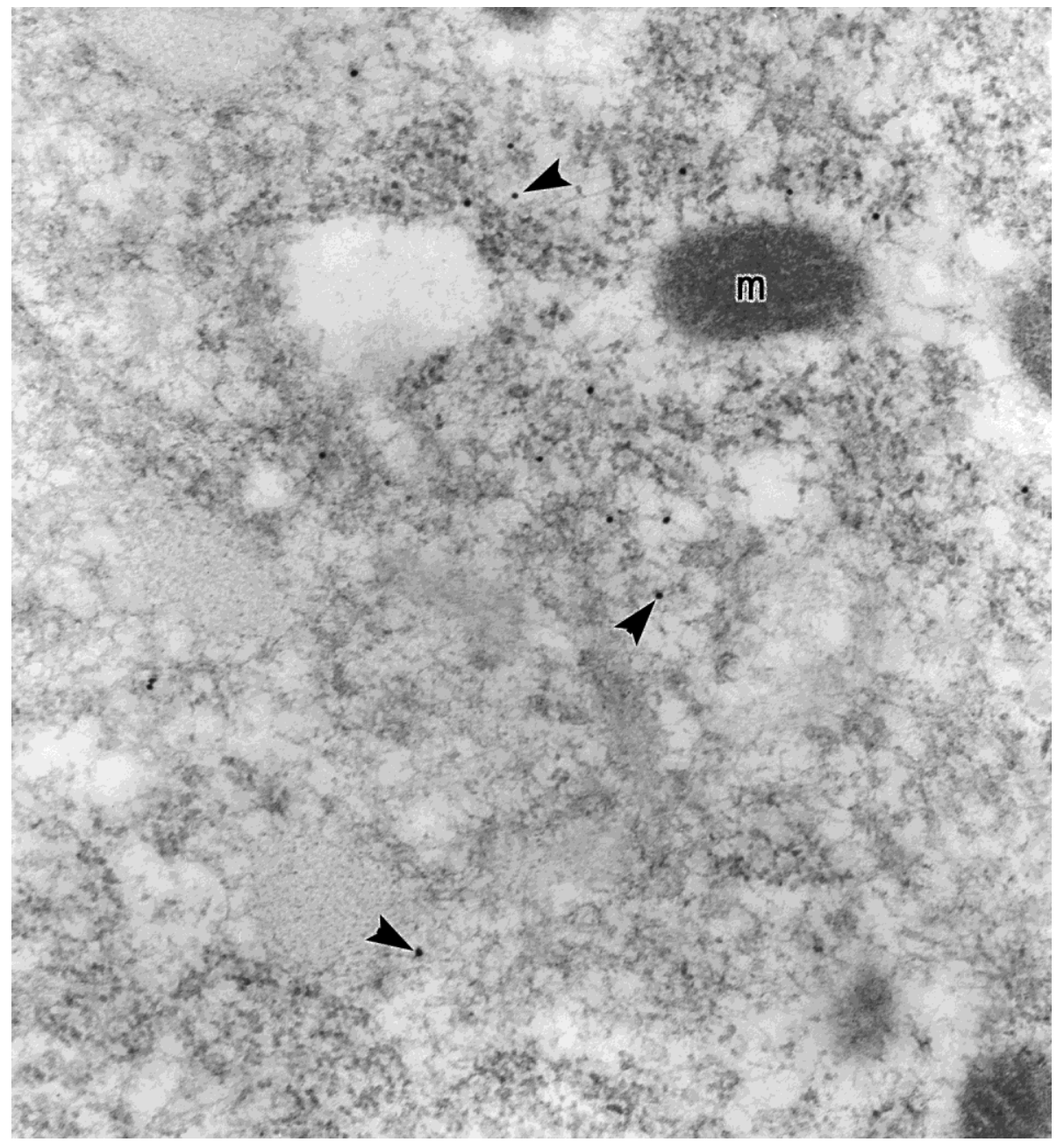

Figura 6- IMUNODETECÇÃO DE OSTEOADERINA. Micrografia eletrônica do citoplasma de osteoblasto adjacente à região da fase fibrilar de mineralização. Algumas partículas de ouro são observadas em distribuição fraca porém homogênea (cabeças de setas). Observe a ausência de marcação na mitocôndria (M). 30.000X 

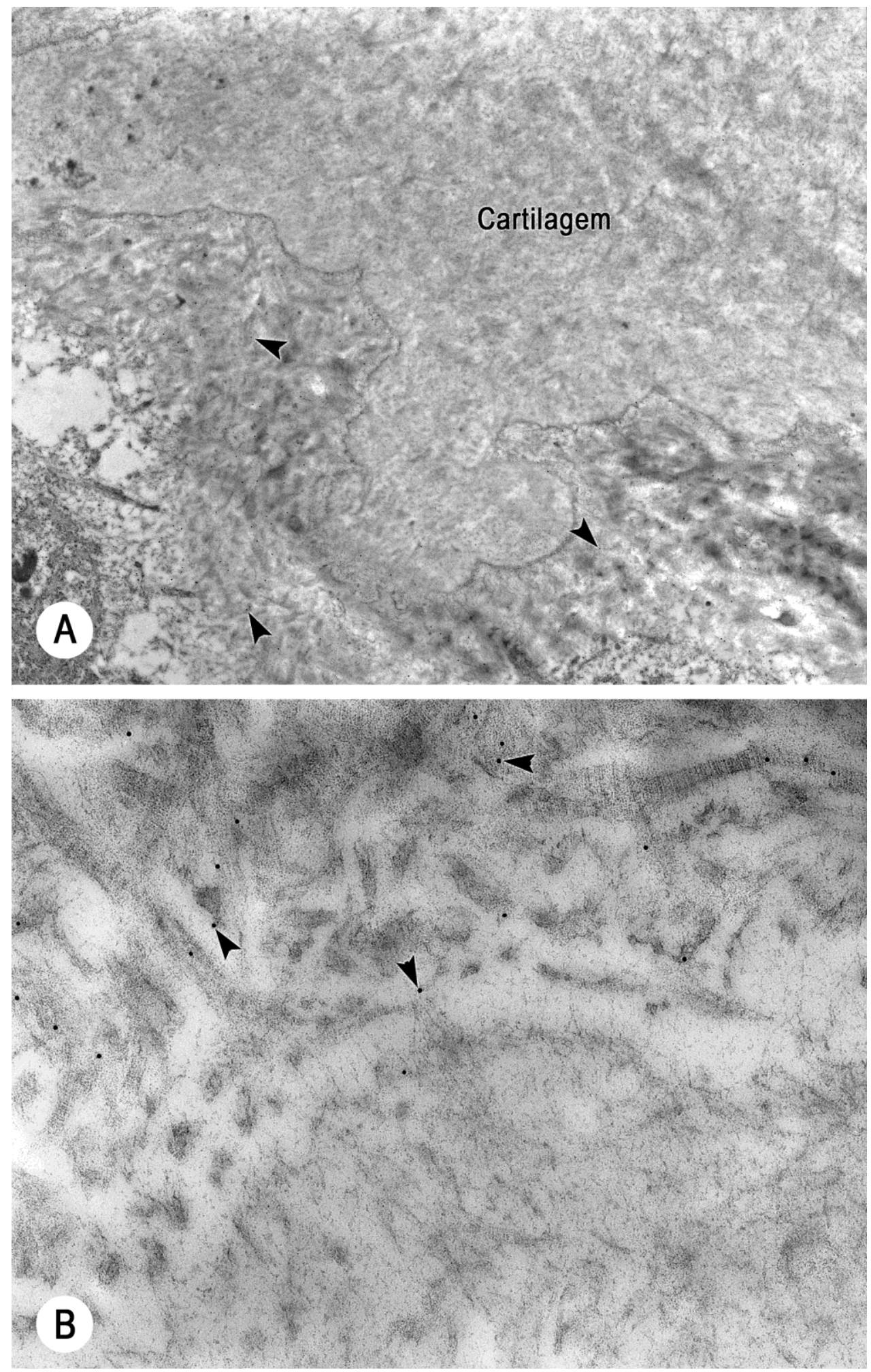

Figura 7- IMUNODETECÇÃO DE OSTEOADERINA. Micrografias Eletrônicas mostrando marcação para OSAD em formação óssea endocondral no côndilo mandibular. A- A interface osso- cartilagem mostra imunomarcação dispersa no osso (cabeças de seta), enquanto a matriz cartilaginosa (Cartilagem) aparece negativa para OSAD. 6.000X. B- Maior aumento de uma região da interface osso- cartilagem, em que a especificidade da reação fica evidente. 30.000X. 


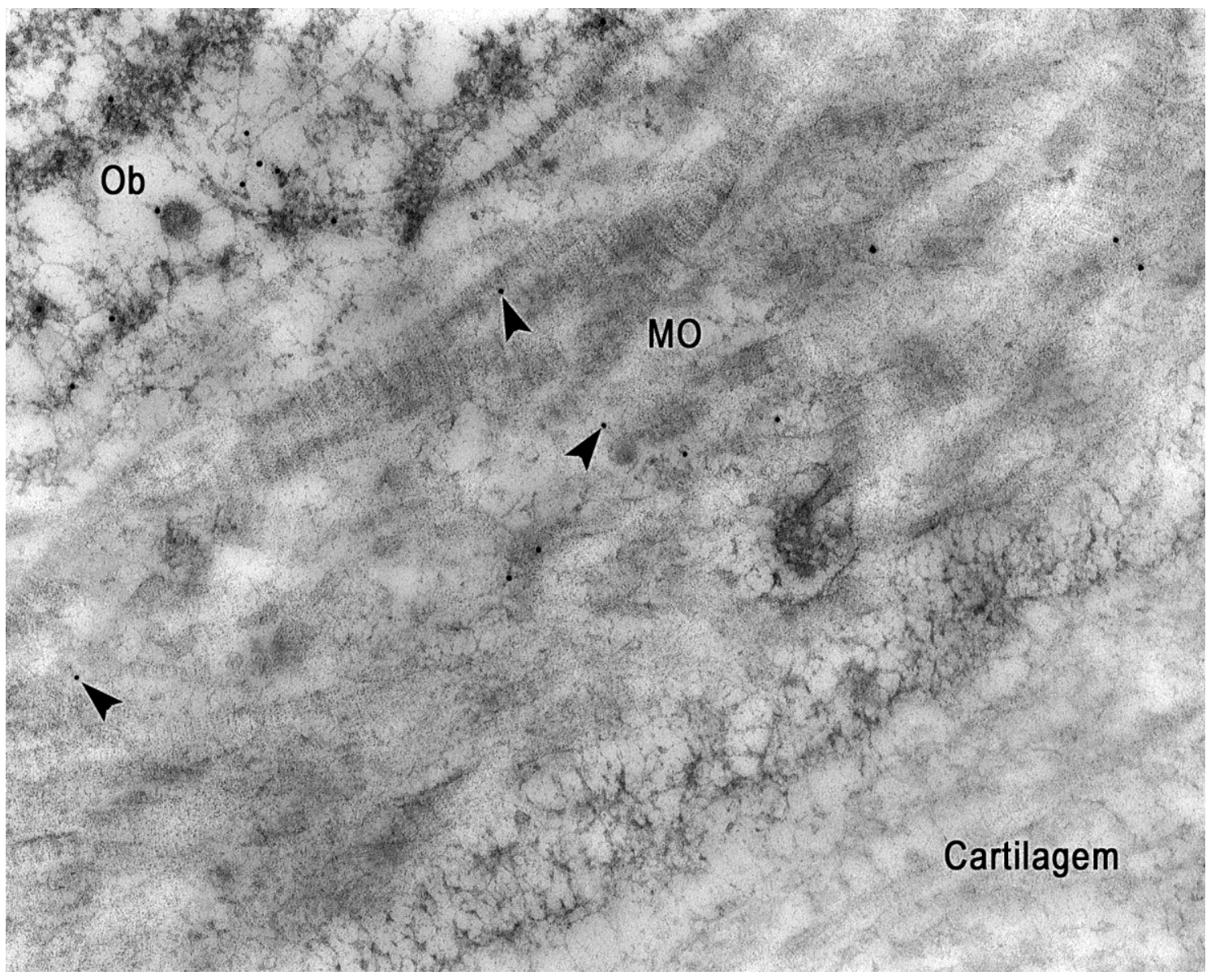

Figura 8- IMUNODETECÇÃO DE OSTEOADERINA. Micrografia Eletrônica da interface osteoblasto/ osso/ cartilagem. As partículas de ouro podem ser notadas no citoplasma da célula secretora de matriz óssea e distribuídas entre as fibras de colágeno desta matriz, enquanto não há imunodetecção na matriz cartilaginosa. $10.000 \mathrm{X}$. 
A osteoaderina foi identificada através de análise por Western-Blotting em osso parietal de fetos com 17, 18 e 21 dias v.i.u. Bandas de aproximadamente $60 \mathrm{KDa}$ foram imunorreativas ao anticorpo policlonal $\mathrm{e}$ mostraram que o osso parietal de embriões com 17 dias possui pouco menos OSAD que aqueles com 18 dias vi.u., enquanto a marcação para os embriões com 21 dias foi fraca. A $\beta$-actina foi usada como controle para confirmar 0 padrão de marcação semelhante em cada amostra (Fig. 9).

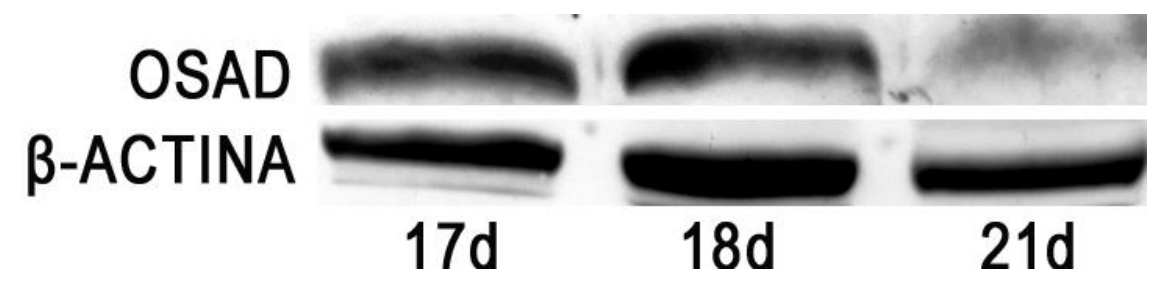

Figura 9- WESTERN BLOTTING. Bandas de aproximadamente $60 \mathrm{KDa}$ foram marcadas com anticorpo policlonal anti- osteoaderina de rato. Um modelo similar de imunorreatividade foi encontrado para os embriões com 17 e 18 dias de v.i.u., enquanto a banda para os embriões com 21 dias v.i.u. teve marcação fraca. A $\beta$-actina foi usada como controle. 
6 DISCUSSÃO 
Este estudo mostrou que a OSAD aparece na matriz extracelular do osso em formação quando a mineralização se inicia nas fibrilas de colágeno, permanecendo como um componente da matriz óssea mineralizada. Enquanto nenhuma marcação para esta $P G$ foi detectada durante a fase vesicular de mineralização na ossificação intramembranosa, a imunomarcação para OSAD foi positiva no citoplasma dos osteoblastos e na matriz em mineralização em ambos os tipos de ossificação durante a fase fibrilar, ou seja, quando os cristais estavam se espalhando nas fibrilas colágenas e nas regiões interfibrilares. $O$ Western blotting confirmou que a OSAD iniciou sua expressão nos estágios em que a fase fibrilar estava se iniciando.

A mineralização inicial na cartilagem e no osso ocorre através da formação das vesículas da matriz, que são liberadas a partir das células formadoras destes tecidos, e, sendo revestidas por membrana, acumulam ativamente em seu interior íons de fosfato de cálcio, até que se precipitam gerando os cristais de hidroxiapatita (ANDERSON, 1995; ANDERSON et al., 2005). A biomineralização, entretanto, é um processo mediado pela matriz orgânica e, por isso, a formação e proliferação dos cristais depende das condições extracelulares, incluindo a concentração de fosfato de cálcio, pH, e a presença das proteoglicanas e proteínas não colágenas, que são diferentes nos diversos tecidos presentes no organismo (GORSKI, 1998; KAWASAKI et al., 2009). Assim, embora a mineralização na ossificação intramembranosa ocorra por vesículas da matriz, assim como a da cartilagem calcificada, cujas vesículas são originadas nos condrócitos hipertróficos (BONUCCl e DEARDEN, 1976); durante a ossificação endocondral o molde cartilaginoso calcificado atua como agente nucleador para a mineralização do osso que se forma sobre ele, não havendo presença de vesículas da matriz originadas do osteoblastos (NAHAR et al., 2008). Portanto, o processo de mineralização do tecido ósseo possui mecanismos diferentes para a ossificação intramembranosa e endocondral. Então, este estudo foi planejado com o intuito de comparar o aparecimento da OSAD durante os dois tipos de formação óssea e correlacioná-lo com os estágios iniciais de mineralização.

Os achados mostraram que a OSAD só esteve presente quando a fase fibrilar de mineralização começou, sugerindo que esta PG atue como 
organizadora da matriz ou como retentora dos cristais de mineral no interior da matriz orgânica; entretanto, sua participação não esteve ligada ao início da deposição de mineral.

Além disso, a presença da OSAD nos estágios de mineralização do colágeno tanto na ossificação intramembranosa quanto na endocondral, e sua ausência na matriz cartilaginosa, sugere que esta $P G$ tenha um papel na nucleação dos cristais juntamente com algumas proteínas acídicas nãocolágenas da matriz óssea (WENDEL et al., 1998; DESHPANDE e BENIASH, 2008; KAVUKCUOGLU et al., 2009; NANCl et al., 2008). Realmente, embora esta função tenha sido atribuída inicialmente às fibras de colágeno, há algum tempo tem se verificado a presença das proteínas não colágenas e proteoglicanas precocemente em áreas de calcificação. Em contraste com a habilidade das PGs de alto peso molecular da cartilagem em inibir a proliferação da hidroxiapatita (REF), as pequenas PGs da matriz óssea estariam relacionadas a vários aspectos da deposição mineral. As duas PPRLs mais conhecidas, decorin e biglican, têm alta afinidade pela hidroxiapatita e possuem diferentes efeitos na biomineralização, regulando a deposição, crescimento e morfologia dos cristais e, algumas vezes, modulando a organização do colágeno. Enquanto a quantidade de decorin na matriz diminui quando a calcificação se inicia, o aumento de biglican indica que ele atua como nucleador dos cristais (WADDINGTON et al., 2003; MOCHIDA et al., 2009; HARUYAMA et al., 2009). Assim, os resultados sugerem que o papel da OSAD na mineralização poderia ser semelhante ao desempenhado pelo biglican, pelo menos em relação à sua presença espaço- temporal na matriz óssea.

$O$ fato de se obter o mesmo modelo de imunomarcação quando os espécimes descalcificados foram incubados com o anticorpo anti- OSAD, revelou que esta $P G$ continua ligada à matriz orgânica com o progresso da mineralização; entretanto não houve aumento na quantidade deste componente à medida que a mineralização avançou. Aliás, durante a padronização da imunocitoquímica pudemos perceber que esta proteoglicana não está em grande quantidade na matriz óssea em nenhum momento, desde sua formação até mesmo depois de terminada a secreção e mineralização da matriz. A distribuição dispersa presente no interior da matriz óssea em estágio 
avançado de mineralização sugere que a OSAD estabelece uma ligação entre os cristais de mineral e os outros componentes orgânicos da matriz óssea, compartilhando esta função com outras proteínas não colágenas da matriz, como a osteopontina (OPN) e a sialoproteína óssea (BSP) (NANCI , 1999).

Em uma análise feita por Ramstad et al., 2003, o padrão de distribuição observado para OSAD foi parecido com aquele da sialoproteína óssea (BSP); entretanto, tanto a BSP quanto a OPN se acumulam na linhas cimentantes e no limite cartilagem- osso (NANCI , 1999), mas isso não foi visualizado para a OSAD, sugerindo que esta proteoglicana teria um papel generalizado em toda matriz óssea, atuando na uniformidade da estrutura da matriz e não em regiões específicas como os dois outros componentes não-colágenos citados. Adicionalmente, sua ausência tanto no interior da matriz cartilaginosa como na interface cartilagem-osso, indica que a OSAD não se liga a nenhum componente da matriz cartilaginosa, sendo restrita aos componentes da matriz orgânica óssea.

A imunomarcação com ouro coloidal permitiu a observação exata da distribuição da OSAD graças à alta resolução da microscopia eletrônica, potencializada pela irradiação com microondas dos espécimes durante a fixação e descalcificação dos mesmos, uma vez que a movimentação das moléculas de água, provocada pelas microondas, aumenta a taxa de penetração do fixador nos tecidos, permitindo o aprimoramento na preservação dos seus diversos componentes, além de uma adicional recuperação antigênica, melhorando assim, o grau de detectabilidade dos componentes não colágenos, mesmo que eles estejam presentes em pequenas quantidades (ARANA-CHAVEZ e NANCI, 2001). Em adição, o Western blotting foi utilizado para fazer uma análise semi-quantitativa da presença de OSAD nas fases iniciais do desenvolvimento do osso parietal. O osso da região condilar não foi utilizado para realização desta técnica, já que, nesta região, não seria possível separar áreas em estágios diferentes de desenvolvimento; sendo assim, as calotas cranianas de animais com idades diferentes foram selecionadas para este fim.

O Western Blotting revelou que o osso parietal de fetos com 17 dias de v.i.u., no qual as vesículas da matriz estão em mineralização, continha uma 
quantidade um pouco menor de OSAD do que o mesmo osso de fetos com 18 dias de v.i.u., quando o mineral está se espalhando a partir das vesículas da matriz calcificadas em direção à matriz colágena circundante. Deve-se levar em consideração que o Western blotting foi realizado com todo o osso parietal em desenvolvimento, isto é, os resultados obtidos representam o conteúdo de OSAD presente na matriz extracelular e nos osteoblastos juntos. Nos animais de 21 dias de v.i.u., possuidores da maior quantidade de conteúdo de mineral nesta amostra, a imunorreatividade para OSAD apresentou menor intensidade que nos espécimes com 18 dias de v.i.u., resultado não condizente com aqueles demonstrados na imunocitoquímica. Se, por um lado isso levanta a possibilidade de que esta $P G$ não pôde ser completamente extraída da matriz óssea mais mineralizada, apontando uma dificuldade técnica, pelo outro indica que as moléculas de OSAD presentes na matriz calcificada ligam-se fortemente à hidroxiapatita, fato que dificultaria sua extração. Aliás, a dificuldade de se extrair moléculas da matriz extracelular nos tecidos calcificados é um fator que deve ser considerado neste estudo. A obtenção de um tampão de lise que conseguisse remover as proteoglicanas de maneira efetiva foi, por si só, uma grande conquista durante estes experimentos.

Este estudo revelou ainda que tanto $\mathrm{O}$ aparecimento quanto a distribuição de OSAD são diferentes do que ocorre com as PGs sulfatadas, como condroitin, heparan, e dermatan-sulfato, que são abundantes na matriz óssea não mineralizada, mas se tornam ausentes quando a matriz se mineraliza, sendo notadas apenas no osteóide, no qual permanecem, evitando, assim, sua mineralização (NAKAMURA et al., 2001). Sendo assim, o papel destes dois tipos de PGs seriam opostos. Enquanto as PGs sulfatadas atuam como inibidoras da mineralização, a OSAD deve participar como nucleadora do mineral ou como organizadora durante a montagem da matriz mineralizada, como comentado acima.

Em resumo, este estudo demonstrou que a OSAD tem o mesmo padrão de expressão, tanto na ossificação intramembranosa, quanto na ossificação endocondral, não sendo responsável por promover a mineralização, mas, provavelmente, executando um papel relacionado à manutenção dos cristais de mineral no interior da matriz orgânica. 
7 CONCLUSÕES 
Os resultados do presente estudo permitem concluir que:

- A OSAD tem o mesmo padrão de expressão na ossificação intramembranosa e endocondral.

- A OSAD não está presente na fase inicial de deposição do mineral, não atuando como promotora na fase vesicular da mineralização.

- A OSAD surge na matriz extracelular do osso em formação durante a fase fibrilar da mineralização, sugerindo que esta $P G$ tenha um papel na nucleação dos cristais de mineral, além de participar na organização da matriz e/ou na retenção do mineral.

- Uma vez ligada à hidroxiapatita, a OSAD permanece como componente da matriz orgânica, provavelmente atuando como mantenedora da matriz mineralizada. 


\section{REFERÊNCIAS}

ASSOCIAÇÃO BRASILEIRA DE NORMAS TÉCNICAS. NBR 6023:

Informação e documentação: referências: elaboração.

Rio de Janeiro, 2002. 
ABZHANOV, A. et al. Regulation of skeletogenic differentiation in cranial dermal bone. Development, v. 134, n. 17, p. 3133-3144, 2007.

ANTONSSON, P.; HEINEGARD, D.; OLDBERG, A. Structure and deduced amino acid sequence of the human fibromodulin gene. Biochem. Biophys. Acta, v. 1174, p. 204-206, 1993.

ARANA-CHAVEZ, V. E.; NANCI, A. High-resolution immunocytochemistry of noncollagenous matrix proteins in rat mandibles processed with microwave irradiation. J. Histochem. Cytochem., v. 49, p. 1099-1109, 2001.

ARANA-CHAVEZ, V. E.; SOARES, A. M. V.; KATCHBURIAN, E. Junctions between early developing osteoblasts of rat calvaria as revealed by freezefracture and ultrathin section electron microscopy. Arch. Histol. Cytol., v. 58, p. 285-292, 1995.

ASZÓDI, A. et al. Mammalian skeletogenesis and extracellular matrix: what can we learn from knockout mice? Cell Struct. Funct., v. 25, p. 73-84, 2000.

BENDAYAN, M. et al. A review of the study of protein secretion applying the protein A-gold immunocytochemical approach. Am. J. Anat., v. 175, p. 379400, 1986.

BENGTSSOM, E. et al. The primary structure of a basic leucine-rich repeat protein, PRELP, found in connective tissues. J. Biol. Chem., v. 270, p. 2563925644, 1995.

BIANCO, P. et al. Expression and localization of the two small proteoglycans biglycan and decorin in developing human skeletal and non-skeletal tissues. J. Histochem. Cytochem., v. 38, p. 1549-1563, 1990.

BOHRMANN, B.; KELLENBERGER, E. Cryosubstitution of frozen biological specimens in electron microscopy: use and applicaion as an alternative to chemical fixation. Micron, v. 32, p. 11-19, 2001. 
BONUCCI, E.; DEARDEN, L.C. Matrix vesicles in aging cartilage. Fed Proc., v.35, n.2, p. 163-168, 1976.

BONUCCI, E. Calcification and silicification: a comparative survey of the early stages of biomineralization. J. Bone Miner. Metab., v. 27, p. 255-264, 2009.

BLOCHBERGER, T. C. et al. cDNA to chick lumican (corneal keratan sulfate proteoglycan) reveals homology to the small interstitial proteoglycan gene family and expression in muscle and intestine. J. Biol. Chem., v. 267, p. 347352, 1992.

BUCHAILLE, R. et al. Expression of the small leucine-rich proteoglycan osteoadherin/osteomodulin in human dental pulp and developing rat teeth. Bone, v. 27, p. 265-270, 2000.

CASTRO, L. S.; ARANA-CHAVEZ, V. E. Visualization of proteoglycans in dentinogenesis with cuprolinic blue and freeze-substitution processing. J. Dent. Res., v. 77, p. 153, 1998 (abstract).

CHUNG, U.I. et al. Distinct osteogenic mechanisms of bones of distinct origins. J. Orthop. Sci. v. 9, p. 410-414, 2004.

COBOURNE, M. T.; SHARPE, P. T. Tooth and jaw: Molecular mechanisms of patterning in the first branchial arch. Arch. Oral Biol., v. 48, p. 1-14, 2003.

COPRAY, J. C. V. M.; DIBBETS, J. M. H.; KANTOMAA, T. The role of condylar cartilage in the development of the temporomandibular joint. Angle Orthod., v. 58, p. 369-380, 1988.

CORPUZ, L. M. Molecular cloning and tissue distribution of keratocan. Bovine corneal keratan sulfate proteoglycan 37A. J. Biol. Chem., v. 271, p. 9759-9763, 1996.

COUBLE, M. L. et al. Immunodetection of osteoadherin in murine tooth extracellular matrices. Histochem. Cell Biol., v. 121, p. 47-53, 2004. 
DANIELSON, K. G. et al. Decorin, epiphycan, and lumican genes are closely linked on murine Chromosome 10 and are deleted in lethal steel mutants. Mamm. Genome, v. 10, p. 201-201, 1999.

DESHPANDE, A.S.; BENIASH, E. Bio- inspired synthesis of mineralized collagen fibrils. Cryst. Growth Des., v. 8, n. 8, p. 3084-3090, 2008.

ERLEBACHER, A. et al. Toward a molecular uderstanding of skeletal development. Cell, v. 80, p. 371-378, 1995.

EZURA, Y. et al. Differential expression of lumican and fibromodulin regulate collagen fibrillogenesis in developing mouse tendons. J. Cell Biol., v. 151, n. 4 , p. $779-787,2000$.

FISHER, L. W.; TERMINE, J. D.; YOUNG, M. F. Deduced protein sequence of bone small proteoglycan I (biglycan) shows homology with proteoglycan II (decorin) and several nonconnective tissue proteins in a variety of species. $\mathbf{J}$. Biol. Chem., v. 264, p. 4571-4576, 1989.

FRANZ-ODENDAAL, T.A.; HALL, B.K.; WITTEN, P.E. Buried alive: how osteoblasts become osteocytes. Dev. Dyn. v. 235 , p.176-190, 2006.

FUNDERBURGH, J. L. Arterial lumican. Properties of a corneal-type keratan sulfate proteoglycan from bovine aorta. J. Biol. Chem., v. 266, p. 24773-24777, 1991.

FUNDERBURGH, J. L. et al. Sequence and structural implications of a bovine corneal keratan sulfate proteoglycan core protein. Protein 37B represents bovine lumican and proteins 37A and 25 are unique. J. Biol. Chem., v. 268, p. 11874-11880, 1993.

GANDHI, N.S.; MANCERA, R.L. The structure of glycosaminoglycans and their interactions with proteins. Chem. Biol. Drug Des., v. 72, p. 455- 482, 2008.

GILBERT, S. F. Developmental Biology. $8^{\text {th }}$ ed. Sunderland: Sinauer Associates, 2006. 
GORSKY, J.P. Is all bone the same? Disctinctive distributins and properties of non-collagenous matrix proteins in lamellar vs. woven bone imply existence of different underlying osteogenic mechanisms. Crit. Rev. Oral Biol. Med., v. 9, n. 2, p. 201-223, 1998.

HARDINGHAM, T. E.; FOSANG, A. J. Proteoglycans: many forms, many functions. Faseb J., v. 6, p. 861-870, 1992.

HARUYAMA, N. et al. Genetic evidence for key roles of decorin and biglycan in dentin mineralization. Matrix Biol., v. 28, p.129-136, 2009.

HAUSSER, H. et al. Selective inactivity of TGF-beta/decorin complexes. FEBS Lett., v. 353, p. 243-245. 1994.

HELMS, J. A.; SCHNEIDER, R. A.. Cranial skeletal biology. Nature, v. 423, p. 326-331, 2003.

HIPPE-SANWALD, S. Impact of freeze substitution on biological electron microscopy. Microsc. Res. Tech., v. 24, p. 400-422, 1993.

HOCKING, A. M.; SHINOMURA, T.; McQUILLAN, D. J. Leucine-rich repeat glycoproteins of the extracellular matrix. Matrix Biol., v. 17, p. 1-19, 1998.

HUNZIKER, E. B. Application of cryotechniques in cartilage tissue. Preservation and immunoelectron microscopy: potentials and problems. Microsc. Res. Techn., v. 24, p. 457-464, 1993.

IOZZO, R. V. The biology of the small leucine-rich proteoglycans. Functional network of interactive proteins. J. Biol. Chem., v. 274, n. 27, p. 18843-18846, 1999.

IOZZO, R. V.; MURDOCH, A. D. Proteoglycans of the extracellular environment: clues from the gene and protein side offer novel perspectives in molecular diversity and function. Faseb J., v.10, p. 598-614, 1996.

JIANG, $X$. et al. Tissue origins and interactions in the mammalian skull vault. Dev. Biol., v. 241, p. 106-116, 2002. 
JUNQUEIRA, L. C.; CARNEIRO, J. Tecido Ósseo. In: Histologia Básica. São Paulo: Editora Guanabara Koogan, 2008, p.136-153.

KARSENTY, G. The complexities of skeletal biology. Nature, v. 423, p. 316318, 2003.

KARSENTY, G.; WAGNER, E. F. Reaching a genetic and molecular understanding of skeletal development. Dev. Cell, v. 2, n. 4, p. 389-406, 2002.

KATCHBURIAN, E.; ARANA-CHAVEZ, V. E. Tecido Ósseo. In: Histologia e Embriologia Oral. São Paulo: Editora Guanabara Koogan, 2004.

KAVUKCUOGLU, N.B.; PATTERSON- BUCKENDAHL, P.; MANN, A.B. Effect of osteocalcin deficiency on the nanomechanics and chemistry of mouse bones. J. Mech. Biomed. Mater., v. 2, n. 4, p. 348- 354, 2009.

KAWASAKI, K.; BUCHANAN, A.V.; WEISS, K.M. Biomineralization in Humans: Making the hard choices in life. Annu. Rev. Genet., v. 43, p. 119-142, 2009.

KNUDSON, C. B.; KNUDSON, W. Cartilage proteoglycans. Semin. Cell Dev. Biol., v. 12, p. 69-78, 2001.

KRONENBERG, H. M. Developmental regulation of the growth plate. Nature, v. 423, p. 332-336, 2003.

KRUSIUS, T.; RUOSLAHTI, E. Small proteoglycans. Proc. Natl. Acad. Sci. USA, v.83, p. 7683-7687, 1986.

KÜHLBRANDT, W.; WILLIAMS, K. A. Analysis of macromolecular structure and dynamics by electron cryo-microscopy. Curr. Opin. Chem. Biol., v. 3, p. 537543, 1999.

LINDE, A. Dentin matrix proteins: Composition and possible functions in calcification. Anat. Rec., v. 224, p. 154-166, 1989.

LOWENSTAM, H.A. Minerals formed by organisms. Science, v. 211, n. 4487, p. 1126-1131, 1981. 
LUCCHINI M. et al. TGF beta 1 signaling and stimulation of osteoadherin in human odontoblasts in vitro. Connect. Tissue Res., v. 43, n. 2-3, p. 345-353, 2002.

MANIA, M.V. et al. A comparative biochemical analysis of glycosaminoglycans and proteoglycans in human orthotopic and heterotopic bone. Life, v. 61, n. 4, p. 447-452, 2009.

MARCHI, F.; LUDER, H. U.; LEBLOND, C. P. Changes in cells'secretory organelles and extracellular matrix during endochondral ossification in the mandibular condyle of the growing rat. Am. J. Anat., v. 190, p. 41-73, 1991.

MARKMANN, A. et al. Influence of decorin expression on transforming growth factor-beta-mediated collagen gel retraction and biglycan induction. Matrix Biol., v. 19, p. 631-636, 2000.

MASSA, L. F.; ARANA-CHAVEZ, V. E. Ultrastructural preservation of rat embryonic dental tissues after rapid fixation and dehydration under microwave irradiation. Eur. J. Oral Sci., v. 108, p. 74-77, 2000.

McEWAN, P. A. Structural correlations in the family of small leucine-rich repeat proteins and proteoglycans. J. Struct. Biol., v. 155, p. 294-305, 2006.

MOCHIDA, Y. et al. Decorin modulates collagen matrix assembly and mineralization. Matrix Biol., v. 28, p. 44-52, 2009.

MURRAY, G. I.; EWEN, S. W. B. A novel method for optimum biopsy specimen preservation for histochemical and immunohistochemical analysis. Am. J. Clin. Pathol., v. 95, p. 131, 1991.

NAHAR, N. N. et al. Matrix vesicles are carriers of bone morphogenetic proteins (BMPs), vascular endothelial growth factor (VEGF), and noncollagenous matrix proteins. J. Bone Miner. Metab., v. 26, p.514-519, 2008.

$\mathrm{NANCl}, \mathrm{A}$. Content and distribution of noncollagenous matrix proteins in bone and cementum: relationship to speed of formation and collagen packing density. J. Struct. Biol., v. 126, n. 3, p. 256-269, 1999. 
$\mathrm{NANCl}, \mathrm{A}$. et al. Immunocytochemistry of matrix proteins in calcified tissues: functional biochemistry on section. Eur. J. Histochem., v. 52, n. 4, p. 201-214, 2008.

OLDBERG, A. et al. A collagen-binding 59-kd protein (fibromodulin) is structurally related to the small interstitial proteoglycans PG-S1 and PG-S2 (decorin). EMBO J., v. 8, p. 2601-2604, 1989.

OLSEN, B. R.; REGINATO, A. M.; WANG, W. Bone development. Annu. Rev. Cell Dev. Biol., v.16, p. 191-220, 2000.

OMELON, S. et al. Control of Vertebrate Skeletal Mineralization by Polyphosphates. PLoS ONE, 4:e5634. doi:10.1371/journal.pone.0005634, 2009.

PETERSSON, U.; HULTENBY, K.; WENDEL, M. Identification, distribution and expression of osteoadherin during tooth formation. Eur. J. Oral Sci., v. 11, p. 128-136, 2003.

RANGELL, L. K.; KELLER, G. A. Application of microwave technology to the processing and immunolabeling of plastic-embedded and cryosections. J. Histochem. Cytochem., v. 48, p. 1153-1159, 2000.

RAMSTAD, V. E. et al. Ultrasctructural distribution of osteoadherin in rat bone shows a pattern similar to that of bone sialoprotein. Calcif. Tissue Int., v. 72, p. 57-64, 2003.

RAOUF, A. et al. Lumican is a major proteoglycan component of the bone matrix. Matrix Biol., v.21, p. 361-367, 2002.

RAOUF, A.; SETH, A. Discovery of osteoblast-associated genes using cDNA microarrays. Bone, v. 30, n. 3, p. 463-471, 2002.

REHN, A.P.; CHALK, A.M.; WENDEL, M. Differential regulation of osteoadherin (OSAD) by TGF-beta1 and BMP-2. Biochem. Biophys. Res. Commun., v. 349, n. 3, p.1057-1064, 2006. 
REHN, A.P. et al. Osteoadherin is upregulated by mature osteoblasts and enhances their in vitro differentiation and mineralization. Calcif. Tissue Int., v. 82, n. 6, p. 454-64, 2008.

SCHAEFER, L.; IOZZO, R.V. Biological functions of the small leucine-rich proteoglycans: from genetics to signal transduction. J. Biol. Chem., v. 283, n. 31, p. 21305-21309, 2008.

SCHAEFER, L.; SCHAEFER, R.M. Proteoglycans: from structural compounds to signaling molecules. Cell. Tissue Res., 2009 Jun 10. [Epub ahead of print].

SCOTT, C. K.; HIGHTOWER, J. A. The matrix of endochondral bone differs from the matrix of intramembranous bone. Calcif. Tissue Int., v. 49, p. 349354, 1991.

SCOTT, J. E. Proteoglycan-fibrillar collagen interactions. Biochem. J., v. 252., p. 313-323, 1988.

SELA, J. et al. The role of matrix vesicles in calcification. In: Bonucci, ed. Calcification in biological systems. Florida: CRC press, 1992.

SHORR, E. A new technic for staining vaginal smears. A simple differential stain. Science, v. 94, p. 545, 1941.

SINGH, M.; DETAMORE, M.S. Biomechanical properties of the mandibular condylar cartilage and their relevance to the TMJ disc. J. Biomech., v. 42 p.405-417, 2009.

SOMMARIN, Y. et al. Ostheoaderin, a cell-binding keratan sulfate proteoglycan in bone, belongs to the family of leucine-rich repeat proteins of the extracelular matrix. J. Biol. Chem., v. 273, p. 16723-16729, 1998.

SUGARS, R. V. et al. Molecular interaction of recombinant decorin and biglycan with type I collagen influences crystal growth. Conn. Tissue Res., v. 44, p. 189195, 2003. 
SUTTAPREYASRI, S. et al. Expression of bone morphogenetic proteins in normal human intramembranous and endochondral bones. Int. J. Oral Maxillofac. Surg., v. 35, p. 444-452, 2006.

SVENSSON, L. et al. Fibromodulin-null mice have abnormal collagen fibrils, tissue, organization, and altered lumican deposition in tendon. J. Biol. Chem., v. 274, p. 9636-9647, 1999.

TAKEUCHI, Y.; KODAMA, Y.; MATSUMOTO, T. Bone matrix decorin binds transforming growth factor-beta and enhances its bioactivity. J. Biol. Chem., v. 269, p. 32634-32638, 1994.

VAN DEN BOS, T. et al. Differences in matrix composition between calvaria and long bone in mice suggest differences in biomechanical properties and resorption. Special emphasis on collagen. Bone, v. 43, p. 459- 468, 2008.

WADDINGTON, R. J. et al. Differential roles for small leucine-rich proteoglycans in bone formation. Eur. Cells Mat., v. 6, p. 12-21, 2003.

WENDEL, M.; SOMMARIN, Y.; HEINEGARD, D. Bone matrix proteins: isolation and characterization of a novel cell-binding keratan sulfate proteoglycan (osteoadherin) from bovine bone. J. Cell Biol., v. 141, p. 839-847, 1998.

YING, S. et al. Characterization and expression of the mouse lumican gene. J. Biol. Chem., v. 272, n. 48, p. 30306-30313, 1997.

ZHOU H.Y. Proteomic analysis of hydroxyapatite interaction proteins in bone.

Ann. N. Y. Acad. Sci., v.1116, p. 323-326, 2007. 